\title{
The Potential Use of Mesenchymal Stem Cells and Their Derived Exosomes for Orthopedic Diseases Treatment
}

\author{
Kosar Malekpour ${ }^{1}$ - Ali Hazrati ${ }^{1}$ - Marziah Zahar ${ }^{2}$ - Alexander Markov ${ }^{3}$. Angelina Olegovna Zekiy ${ }^{4}$ \\ Jamshid Gholizadeh Navashenaq ${ }^{5} \cdot$ Leila Roshangar $^{6} \cdot$ Majid Ahmadi $^{6}$ (D)
}

Accepted: 11 May 2021 / Published online: 24 June 2021

(c) The Author(s), under exclusive licence to Springer Science+Business Media, LLC, part of Springer Nature 2021

\begin{abstract}
Musculoskeletal disorders (MSDs) are conditions that can affect muscles, bones, and joints. These disorders are very painful and severely limit patients' mobility and are more common in the elderly. MSCs are multipotent stem cells isolated from embryonic (such as the umbilical cord) and mature sources (such as adipose tissue and bone marrow). These cells can differentiate into various cells such as osteoblasts, adipocytes, chondrocytes, NP-like cells, Etc. Due to MSC characteristics such as immunomodulatory properties, ability to migrate to the site of injury, recruitment of cells involved in repair, production of growth factors, and large amount production of extracellular vesicles, these cells have been used in many regenerativerelated medicine studies. Also, MSCs produce different types of EVs, such as exosomes, to the extracellular environment. Exosomes reflect MSCs' characteristics and do not have cell therapy-associated problems because they are cell-free. These vesicles carry proteins, nucleic acids, and lipids to the host cell and change their function. This review focuses on MSCs and MSCs exosomes' role in repairing dense connective tissues such as tendons, cartilage, invertebrate disc, bone fracture, and osteoporosis treatment.
\end{abstract}

Keywords MSCs $\cdot$ Exosomes $\cdot$ MSDs $\cdot$ Orthopedic disease $\cdot$ Regenerative medicine

$\begin{array}{ll}\text { Abbreviations } \\ \text { MSDs } & \text { Musculoskeletal disorders } \\ \text { MSCs } & \text { Mesenchymal stem cells } \\ \text { DLS } & \text { Dynamic light scatting } \\ \text { SEM } & \text { Surface electron microscopy } \\ \text { TEM } & \text { Transient electron microscopy } \\ \text { NSAIDs } & \text { Nonsteroidal anti-inflammatory } \\ \text { IDO } & \text { Indolamine 2,3-dioxygenese }\end{array}$

Majid Ahmadi

Ahmadi.m@tbzmed.ac.ir

1 Department of Immunology, Faculty of Medical Sciences, Tarbiat Modares University, Tehran, Iran

2 Social Security Centre of Excellence, School of Business Management, College of Business, Universiti Utara Malaysia, Sintok Kedah, Malaysia

3 Tyumen State Medical University, Tyumen, Russia

4 Department of Prosthetic Dentistry, Sechenov First Moscow State Medical University, Moscow, Russia

5 Noncommunicable Diseases Research Center, Bam University of Medical Sciences, Bam, Iran

6 Stem Cell Research Center, Tabriz University of Medical Sciences, Tabriz, Iran

$\begin{array}{ll}\text { GAPDH } & \text { Glyceraldehyde 3-phosphate dehydrogenase } \\ \text { PGK } & \text { Phosphoglycerate kinase } \\ \text { PGM } & \text { Phosphoglucomutase } \\ \text { ENO } & \text { Enolase } \\ \text { TLR } & \text { Toll-like receptors } \\ \text { IL-1 } & \text { Interleukin-1 } \\ \text { TNF } & \text { Tumor Necrosis Factor } \\ \text { BMP } & \text { Bone morphogenic protein } \\ \text { HIF } & \text { Hypoxic induced factor } \\ \text { VEGF } & \text { Vascular endothelial growth factor } \\ \text { COL1 } & \text { Collagen Type 1 } \\ \text { MAPK } & \text { Mitogen-activated protein kinase } \\ \text { LncRNA } & \text { Long non-coding RNA } \\ \text { TGF- } \beta & \text { Transforming growth factor-beta } \\ \text { NF-kB } & \text { Nuclear factor kappa-B } \\ \text { NP } & \text { Nucleus pulposus } \\ \text { ECM } & \text { Extracellular matrix } \\ \text { IDD } & \text { Intervertebral disc disease } \\ \text { MMPs } & \text { Matrix metalloproteinase } \\ \text { HSPs } & \text { Heat shock protein } \\ \text { PTEN } & \text { Phosphatase and tensin homolog } \\ \text { AGEs } & \text { Advanced glycation end products } \\ & \end{array}$


ER NLRP Endoplasmic reticulum Necleotide-binding oligomerization domain, Leucine-rich Repeat and Pyrin domain containing

\section{Introduction}

Orthopedic diseases are the most common cause of disability worldwide and include muscles, bones, nerves, joints, ligaments, tendons, and other connective tissue diseases. In general, damage to these tissues is due to their wounding or degeneration. The prevalence of these diseases increases with age, and The prognosis in these patients is usually poor [1]. People with musculoskeletal diseases (MSDs) have pain in different parts of the body with similar characteristics and prognosis and may respond to similar treatments [2]. Among the various treatments, we can mention non-pharmacological therapies, complementary therapies, pharmacological therapies, surgery, cell therapy, and combination therapy. These injuries are associated with a lot of pain, and there is usually no definitive cure for them, and the available treatments are usually used to reduce the pain. These include the use of corticosteroids, simple painkillers, and nonsteroidal anti-inflammatory drugs (NSAIDs) [3]. However, the effectiveness of these treatments is unclear and inconsistent. Nowadays, Cell therapy is one of the methods used in regenerative medicine, such as musculoskeletal diseases.

MSCs are used in the regeneration of different tissues due to their characteristics [4]. Self-renewability and the ability to differentiate into various cells are two characteristics of stem cells, and also they can be seen in MSCs [5]. These cells proliferate in vitro as plastic-adherent heterogeneous cells and have a fibroblast-like morphology. MSCs form colonies in vitro cultures and can be differentiated into bone, cartilage, and fat cells. However, researchers are trying to find and use all the potential of MSCs to create safe and alternative treatments. Therapeutic amplification of circulatory MSC, genomic manipulation of MSCs, combination therapy of mesenchymal stem cells with drugs, and use of their exosomes are examples of these efforts [6].

The use of MSCs derived exosomes has also been expanded to reduce cell therapy's side effects. Exosomes are lipid bilayer nanoparticles that, because they have a membrane similar to the body's cells, easily fuse with them and transfer their contents into target cells.

This article will discuss studies of MSCs and their exosomes role in bone diseases treatment such as osteoporosis and bone fractures and various types of degenerative diseases of dense connective tissue treatment, including cartilage, tendon, ligament, and Intervertebral disc.

\section{Mesenchymal Stem Cell}

MSCs, like other stem cells, are undifferentiated and can divide during self-renewal and differentiate into different cell types and tissues [7]. The sources of these cells are divided into three categories according to the place of collection. 1) Prenatal-derived sources such as placenta, umbilical cord, and umbilical cord blood 2) Embryonic sources such as amniotic fluid and embryonic tissue 3 ) Adult sources such as bone marrow, adipose tissue, muscle, and peripheral blood. The secretion of soluble factors from MSCs is another way that plays a role in the homeostasis of various tissues [8]. Different tissues derived MSCs' positive and negative markers are listed in Table 1.

Under standard conditions, MSCs have the ability to adhere to plastic [9]. They have also been shown to differentiate into fatty adipose cells, osteoblasts, chondrocytes, tenocytes, skeletal myocytes, heart muscle cells, smooth muscle cells, and even neurons $[10,11]$. Since the beginning of studies on stem cells, special attention has been paid to MSCs from various sources. Therefore, these cells have become pioneers in the field of stem cell therapy studies.

\section{Mesenchymal Stem Cell and the Immune System}

Interestingly, MSCs exhibit anti-inflammatory properties when exposed to high levels of pro-inflammatory cytokines but enhance inflammatory responses when exposed to low levels of interferon-gamma and tumor necrosis factor-alpha (TNF- $\alpha)[12,13]$. The physiological properties of MSCs make them commonly used for tissue regeneration, transplant rejection, autoimmune diseases, and sepsis. Due to easy access, isolation, culture, and storage, they have become one of the main cell therapy options. Other functions of MSCs include migration to damaged tissues, increased angiogenesis, prevention of fibrosis, neuroprotective effects, suppression of the immune system, and suppression of hematopoietic stem cell apoptosis has a role in their therapeutic application [14].

These cells have been used for the treatment of skeletal diseases, multiple sclerosis, liver cirrhosis, rheumatoid arthritis, Alzheimer's, transplant rejection, graft versus host disease, inflammatory bowel disease, type 1 diabetes, asthma, and allergic diseases, etc. [15]. Table 2 shows some clinical trials in the field of MSCs in musculoskeletal diseases therapy (Table 2).

Although many studies have used MSCs as a treatment for various tissue disorders, problems such as tumorigenesis, fibrosis, pro-inflammatory conditions in the treated cell tissue, cell rejection and injection toxicity, functional 
Table 1 Various tissues MSCs positive and negative surface markers

\begin{tabular}{lll}
\hline MSC tissue source & Positive markers & Negative markers \\
\hline Adipose tissue & CD105, CD73, CD36, CD90, CD44, CD29, CD151, & CD45, CD34, CD14, CD11b, CD19, HLA-DR, CD34, \\
& CD49d [149, 150] & CD38, CD31, CD106 [150-152] \\
Bone marrow & CD29, CD31, CD44, CD49a, CD49b, CD49c, CD49d, & CD11a, CD11b, CD13, CD14, CD19,CD34, CD45,CD133,, \\
& CD49e, CD51, CD54, CD58, CD61, CD71, CD73, & CD31, CD86, HLA-DR [153] \\
& CD90, CD102, CD104, CD105, CD106, CD120a, & \\
& CD120b, CD121a, CD124, CD146, CD166, CD221, & \\
Umbilical cord blood & CD29, CD44, CD73, CD90, CD105, CD166 [156, 157] & CD14, CD31, CD34, CD45,CD106, HLA-DR [156] \\
Synovial fluid & CD9, CD10, CD13, CD44, CD54, CD55, CD90, CD105, & CD14, CD45, CD34, CD117, CD62e, CD20, CD113, HLA- \\
& CD166, D7-FIB, CD49a, CD147, CD73, CD140a, CD49 & DR, CD68, CD31, ALP, CD62, HLA-DR [158, 159] \\
Dental pulp & CD29, CD44, CD105, CD146, CD117 and STRO-1, & \\
& SSEA-4, CD146, CD73, CD44, CD10, CD123 [160, & \\
161] & \\
Wharton jelly & CD90, CD105, CD73, CD29, CD44 [9, 162, 163] & CD3, CD34, CD45, CD14, CD19, HLA-DR [163] \\
Amnion & CD73, CD29, CD49f, Oct4, Nanog, Sox2, SSEA-3, SSEA- CD14, CD20, CD34, CD45 [165] & \\
& 4, Rex1 [164] & \\
\hline
\end{tabular}

erosion, and the restricted ability of MSCs to differentiate are the barriers that can greatly overwhelm the therapeutic efficacy of these cells. MSCs, affect the immune system cells function and reduces inflammation and modulates injury cite microenvironment. Mesenchymal stem cells produce the IL-1B receptor, which inhibits $B$ cell differentiation by trapping interleukin 1 , stimulates macrophage type 2 responses, and increases their differentiation into M2 [16]. Also, they produces IL-10 and stimulates the expression of MHC class II, CD45, and CD11 on monocytes, reduces T cell responses and increases their differentiation into Treg [17], and suppress DC migration and maturation.

Table 2 Clinical trials that use mesenchymal stem cells to treat in various diseases

\begin{tabular}{|c|c|c|c|}
\hline & Study Title & Information provided by (Responsible Party): & $\begin{array}{l}\text { ClinicalTrials. } \\
\text { gov Identifier }\end{array}$ \\
\hline 1 & $\begin{array}{l}\text { Mesenchymal Stem Cells Transplantation in Newly Diag- } \\
\text { nosed Type-1 Diabetes Patients (MSCTXT1DM) }\end{array}$ & $\begin{array}{l}\text { Tehran University of Medical SciencesIranian Stem- } \\
\text { Cell Council }\end{array}$ & $\underline{\text { NCT04078308 }}$ \\
\hline 2 & $\begin{array}{l}\text { Mesenchymal Stem Cells for Progressive Multiple Sclerosis } \\
\text { Sweden }\end{array}$ & Ellen Iacobaeus, Karolinska Institutet & $\underline{\text { NCT03778333 }}$ \\
\hline 3 & $\begin{array}{l}\text { Allogenic Bone Marrow Mesenchymal Stem Cells Infusion } \\
\text { in Patients With Steroid-refractory GVHD }\end{array}$ & $\begin{array}{l}\text { National Institute of Blood and Marrow Transplant } \\
\text { (NIBMT), Pakistan }\end{array}$ & NCT02824653 \\
\hline 4 & Bone Regeneration With Mesenchymal Stem Cells & $\begin{array}{l}\text { Alejandro Gonzalez-Ojeda, Instituto Mexicano del Seguro } \\
\text { Social }\end{array}$ & NCT02755922 \\
\hline 5 & $\begin{array}{l}\text { Mesenchymal Stem Cells for the Treatment of Rectovaginal } \\
\text { Fistulas in Participants With Crohn's Disease (RVF) }\end{array}$ & Amy Lightner, The Cleveland Clinic & NCT04519697 \\
\hline 6 & $\begin{array}{l}\text { Mesenchymal Stem Cell Transplantation for Acute-on- } \\
\text { chronic Liver Failure }\end{array}$ & Han Ying, Xijing Hospital of Digestive Diseases & $\underline{\text { NCT03668171 }}$ \\
\hline 7 & $\begin{array}{l}\text { Mesenchymal Stem Cell for Acute Respiratory Distress } \\
\text { Syndrome Due for COVID-19 }\end{array}$ & $\begin{array}{l}\text { Martín Iglesias, Instituto Nacional de Ciencias Medicas y } \\
\text { Nutricion Salvador Zubiran }\end{array}$ & NCT04416139 \\
\hline 8 & $\begin{array}{l}\text { Clinical Trial of Umbilical Cord Mesenchymal Stem Cell } \\
\text { Transfusion in Decompensated Liver Cirrhosis }\end{array}$ & Shandong Qilu Stem Cells Engineering Co., Ltd & $\underline{\text { NCT03529136 }}$ \\
\hline 9 & Mesenchymal Stem Cells for Multiple Sclerosis & Ellen Iacobaeus, Karolinska Institutet & $\underline{\text { NCT01730547 }}$ \\
\hline 10 & $\begin{array}{l}\text { Use of Mesenchymal Stem Cells in Inflammatory Bowel } \\
\text { Disease }\end{array}$ & Hanan Jafar, University of Jordan & $\underline{\text { NCT03299413 }}$ \\
\hline 11 & $\begin{array}{l}\text { Allogeneic Human Mesenchymal Stem Cells for Alzhei- } \\
\text { mer's Disease }\end{array}$ & Stemedica Cell Technologies, Inc & $\underline{\mathrm{NCT} 02833792}$ \\
\hline 12 & $\begin{array}{l}\text { Allogeneic Human Cells (hMSC) Via Intravenous Delivery } \\
\text { in Patients With Mild Asthma (ASTEC) }\end{array}$ & Marilyn Glassberg, University of Miami & $\underline{\text { NCT03137199 }}$ \\
\hline
\end{tabular}

GVHD Graft Versus Host Disease, RVF Rectovaginal Fistulas, $h M S C$ Human Mesenchymal Stem cell 
Mesenchymal stem cells continuously secrete indolamine 2,3-dioxygenase (IDO). Sequential reduction of tryptophan by IDO inhibits allogeneic $\mathrm{T}$ cell responses, stimulates IL-4 secretion in Th2 cells, and reduces IFN-g production by Th1 cells [18]. These cells also inhibit T-cell responses by secreting PD-L1 and induce apoptosis and non-response in these cells. Besides, mesenchymal stem cells inhibit NK cells' response by secreting factors such as prostaglandin E2, TGF-B1, NO, and IL-6 $[12,19]$.

\section{Mesenchymal Stem Cell-derived Exosomes}

Due to the mentioned limits, in recent years, scientists have turned their attention to the indirect use of MSCs, which are based on extracellular vesicles (EVs) derived from these cells [10]. Apoptotic body, microvesicles (MVs), and exosomes are three types of EVs and divided based on their size, content, and formation [20]. Apoptotic bodies are $50-4000 \mathrm{~nm}$ in size and are typically produced in the last stage of apoptosis from apoptotic cells. These EVs are heterogeneous and contain membrane contents (such as phosphatidylserine), nuclear material, and cellular organelles [21]. Unlike apoptotic bodies, microcycles are shedding directly from the healthy cells membrane. Like the apoptotic body, these EVs have a heterogeneous morphology and their size range from 100 to $1000 \mathrm{~nm}$. Microvesicles can affect the expression of genes by transmitting mi-RNA to neighboring cells. Besides, because MVs release from the cell is not dependent on endocytosis, they lack endocytosisrelated proteins [22]. Exosomes by $30-120 \mathrm{~nm}$ size are the smallest EVs and are produce during late endosome membrane inward invagination and the multiple vesicular bodies (MVBs) formation [23]. After forming exosomes inside MVBs, they are secreted to the extracellular environment through endocytosis by MVBs membrane fusing with cell membrane [24]. Today, exosomes are divided into three groups based on size: large exosomes (exo-L size is between 90 to $120 \mathrm{~nm}$ ), small exosomes (exo-S size is between $60-80 \mathrm{~nm}$ ), and exomers which are $35 \mathrm{~nm}$ in size [25].

MSCs produce large amounts of exosomes compared to other cells, which makes them clinically viable for exosome separation and therapy [26]. Exosomes have common markers that seen in them and can be referred to as tetraspanins (CD63, CD9, CD81, CD82), fusion involved proteins (flotillins, CD9, annexin, GTPases), adhesion molecules, gap junction related proteins (Connexins-43) [27], heat shock proteins (HSC70 and HSC90), MHC-1, MHC-2, membrane transporters (GTPases), Rab proteins [28], lysosomal proteins (Lamp2b) and proteins involved in multivesicular body biogenesis (Alix and TSG101) [29, 30].

Exosomes are separated in a variety of ways, such as ultracentrifugation, density gradient centrifugation, pegylation-based methods, and the use of kits. After characterizing the exosome through various methods such as dynamic light scatting (DLS), scanning electron microscopy(SEM), transmission electron microscopy(TEM), ELISA, it can be used for therapeutic applications.

Exosomes' uses have not the risk of genetic instability and immunosuppression following allogeneic administration in the in vivo models. Studies show that exosome therapy can be considered a new strategy to overcome stem cell therapy deficiencies [31].

Exosomes are one of the paracrine cellular communication vesicles. They can carry cytokines, chemokines, growth factors, different enzymes, different signaling molecules, miRNAs, lipids, and transcription factors by a lipid bilayer membrane. Based on studies, cargos present in MSC exosomes include enzymes involved in the synthesis of ATP (glyceraldehyde 3-phosphate dehydrogenase (GAPDH), phosphoglycerate kinase (PGK), phosphoglucomutase (PGM), enolase (ENO) [32], angiogenesis stimulating enzymes (VEGF, inducer extracellular matrix metalloproteinase (EMMPRIN) and MMP-9) [33], Various transcription factors (transcription factor with Octamer 4 (Oct-4), HoxB4 and Rex-1) [31], tumor growth inhibitory miRs (miR-23b, miR-214, miR-451, miR-223, MiR-31, miR-24, miR-125b and miR-122) [34] and inflammation regulating miRs (miR-155 and miR-146) [35]. Thus, bilayer lipids protect nucleic acids and proteins from degradation in the extracellular environment, enabling efficient transport. Table 3 shows some new studies that used MSCs derivedexosomes to repair and regenerate tissue in orthopedic diseases (Table 3).

Exosomes are smaller and less complex than their parent cells and also have less protein in the membrane. Therefore, they are easier to separate and store and have lower immunogenicity than cell therapy [36]. Furthermore, exosomes systemically are less likely to be trapped in the lungs or liver. Exosomes can transmit information through various ways, such as juxtacrine and solution signaling [37]. Exosomes have advantages over the use of their source cells: 1) Their use prevents the transfer of cells that may contain immunogenic molecules and even mutated or damaged DNA. 2) Exosomes are Nano-sized, and They can enter any organ and move easily inside it, while the cells are larger and cannot migrate to the site of injury through capillaries.3) Exosomes, due to the presence of homing molecules on Their surface, can migrate to different parts of the body. 4) Because exosomes are native to the body, their surface has biochemical properties similar to their derived cells, enabling them to prevent phagocytosis, fusion with cell membranes, and lysosomal fusion [38].

Due to the mentioned features, MSCs-derived exosomes have become one of the dynamic fields in regenerative 
Table 3 New studies used mesenchymal stem cells derived-exosomes to repair and regenerate tissue in orthopedic diseases

\begin{tabular}{|c|c|c|c|c|c|c|}
\hline number & Study name & MSC source & Affected tissue & Study type & Exosome dose & reference \\
\hline 1 & $\begin{array}{l}\text { Bone marrow mesenchymal stem cell- } \\
\text { derived exosomes promote tendon } \\
\text { regeneration by facilitating the prolif- } \\
\text { eration and migration of endogenous } \\
\text { tendon stem/progenitor cells }\end{array}$ & Bone marrow & tendon & In vivo and in vitro & $5 \mu \mathrm{L}$ of exos $(4 \mu \mathrm{g} / \mu \mathrm{L})$ & [166] \\
\hline 2 & $\begin{array}{l}\text { TGF-b1-containing exosomes derived } \\
\text { from bone marrow mesenchymal } \\
\text { stem cells promote proliferation, } \\
\text { migration, and fibrotic activity in } \\
\text { rotator cuff tenocytes }\end{array}$ & Bone marrow & tendon & In vitro & $20 \mu \mathrm{g} / \mathrm{mL}$ & {$[167]$} \\
\hline 3 & $\begin{array}{l}\text { Mesenchymal stem cell-derived } \\
\text { exosomes ameliorate intervertebral } \\
\text { disc degeneration via anti-oxidant } \\
\text { and anti-inflammatory effects }\end{array}$ & bone marrow & intervertebral disc & In vivo & $100 \mu \mathrm{g} / \mathrm{ml}$ & {$[132]$} \\
\hline 4 & $\begin{array}{l}\text { Hypoxic mesenchymal stem cell- } \\
\text { derived exosomes promote bone } \\
\text { fracture healing by the transfer of } \\
\text { miR-126 }\end{array}$ & umbilical cord & bone & in vitro and in vivo & $100 \mu \mathrm{g} / \mathrm{mL}$ & [74] \\
\hline 6 & $\begin{array}{l}\text { MSC exosomes mediate cartilage } \\
\text { repair by enhancing proliferation, } \\
\text { attenuating apoptosis and modulating } \\
\text { immune reactivity }\end{array}$ & $\begin{array}{l}\text { E1-MYC } 16.3 \\
\text { human embry- } \\
\text { onic stem cell } \\
\text { derived } \\
\text { MSC line }\end{array}$ & cartilage & In vitro & $10 \mu \mathrm{g} / \mathrm{ml}$ & [115] \\
\hline 7 & $\begin{array}{l}\text { Sphingosine-1-phosphate mediates the } \\
\text { therapeutic effects of bone marrow } \\
\text { mesenchymal stem cell-derived } \\
\text { microvesicles on articular cartilage } \\
\text { defect }\end{array}$ & bone marrow & cartilage & in vitro and in vivo & $100 \mu \mathrm{g} / \mathrm{mL}$ & [168] \\
\hline 8 & $\begin{array}{l}\text { Human bone mesenchymal stem cells- } \\
\text { derived exosomes overexpressing } \\
\text { microRNA-26a-5p alleviate osteoar- } \\
\text { thritis via down-regulation of PTGS2 }\end{array}$ & umbilical cord & cartilage & In vitro and in vivo & unclear & [169] \\
\hline 9 & $\begin{array}{l}\text { Exosomes derived from miRNA-210 } \\
\text { overexpressing bone marrow mesen- } \\
\text { chymal stem cells protect lipopol- } \\
\text { ysaccharide-induced chondrocytes } \\
\text { injury via the NF- } \mathrm{KB} \text { pathway }\end{array}$ & Bone marrow & ligament & In vitro & unclear & {$[170]$} \\
\hline 10 & $\begin{array}{l}\text { Intra-Articular Injections of Mesenchy- } \\
\text { mal Stem Cell Exosomes and Hya- } \\
\text { luronic Acid Improve Structural and } \\
\text { Mechanical Properties of Repaired } \\
\text { Cartilage in a Rabbit Model }\end{array}$ & $\begin{array}{l}\text { E1-MYC } 16.3 \\
\text { human embry- } \\
\text { onic stem } \\
\text { cell-derived } \\
\text { MSC line }\end{array}$ & ligament & In vivo & $200 \mu \mathrm{g} / \mathrm{mL}$ & {$[171]$} \\
\hline
\end{tabular}

$T G F-\beta$ Transforming growth factor-B, MSC Mesenchymal stem cell, PTGS2 Prostaglandinendoperoxide synthase $2, N F-\kappa B$ Nuclear factor kappa-B

medicine. Tissue destruction in many orthopedic diseases is one of the most important causes of loss of function. If we repair these tissues, their function will be mostly reversible. MSC-derived exosomes' therapeutic effect in heart, kidney, lung, skin, brain, liver, autoimmune, and musculoskeletal diseases has been demonstrated [39]. These exosomes can be used to treat various diseases such as type 1 diabetes, macular degeneration, chronic kidney disease, ischemic stroke [40], Alzheimer's [41], multiple sclerosis [42], sepsis, hepatitis [43], Chronic liver disease [36], skin disease [44] and musculoskeletal disease.
MSCs-derived exosomes have been shown to have therapeutic effects by modulating the immune system, stimulating cell proliferation, promoting angiogenesis, preventing apoptosis, and suppressing oxidative stress [5]. These exosomes help to homeostasis maintenance and cell repair by providing and transporting active enzymes to restore normal cell activity [45]. Proteomic analyses of MSCs exosomes show the presence of more than 200 immunomodulatory molecules in them [46]. Also, these exosomes increase proliferation in the target cell and prevent apoptosis by activating the Ras/Raf/MEK/ ERK and PTEN/PI3K/AKT/mTOR signaling pathways [47]. 
Apart from the therapeutic ability, MSC-derived exosomes have the ability to migrate to lesion sites. It is also possible to modify the surface molecules of exosomes to migrate more and better to the site of injury [48]. This feature of exosomes makes them a good vehicle and a transport system that can deliver drugs directly to the site of disease [49]. Systemic exosome injections, such as intravenous, intraperitoneal, or subcutaneous, resulting in the rapid clearance of exosomes from the bloodstream and their accumulation in the liver, spleen, lungs, and gastrointestinal tract [50, 51]. Also, as a significant point, regardless of the injection route, most of the systemically injected exosomes are rapidly taken up by macrophages in the reticuloendothelial system and eliminate from the body [52]. Therefore, the biological distribution of exosomes after systemic administration can be divided into two stages. 1) Rapid distribution in liver, spleen, and lungs approximately $30 \mathrm{~min}$ after administration. 2) Removal of exosomes by hepatic and renal processing 1 to $6 \mathrm{~h}$ after administration [53]. The half-life of exosomes is administered topically (Such as the skin surface and ocular surface) is shorter due to their cleansing by fluids (sweat and tears) and exposure to external factors [54]. Figure 1 shows the main mechanisms involved in the therapeutic applications of MSCs and their exosomes (Fig. 1), and Table 4 describes some mechanisms of MSC and MSC-derived exosomes involved in regenerative medicine.

\section{MSCs and their Exosomes Role in Bone Regeneration}

Bone regeneration is a complex process, and many cells, such as osteoblasts, osteoclasts, endothelial cells, chondrocytes, and MSCs, play a role in this process. Bone regeneration may occur in two ways: 1) intramembranous ossification that creates flat bones, and 2) endochondral ossification creates long bones [55]. Intramembranous osteogenesis performed by MSCs-derived osteoblasts direct calcification of bone. But endochondral ossification has a complex step that is regulated by chondrocytes [8]. Bone regeneration does not always happen wholly and correctly. Therefore, to increase the efficiency of bone repair, various treatments have been used. One of these treatments is the use of MSCs, which have been highly attentive for about two decades. Different

\title{
The main mechanism of MSCs and thier exosome in treatment of orthopedic diseases
}

\author{
Immune regulation \\ $\downarrow$ Proinflamatory cytocines \\ $\uparrow$ Treg differentiation \\ $\uparrow \mathrm{M} 2 \mathrm{MQ}$ differentiation
}
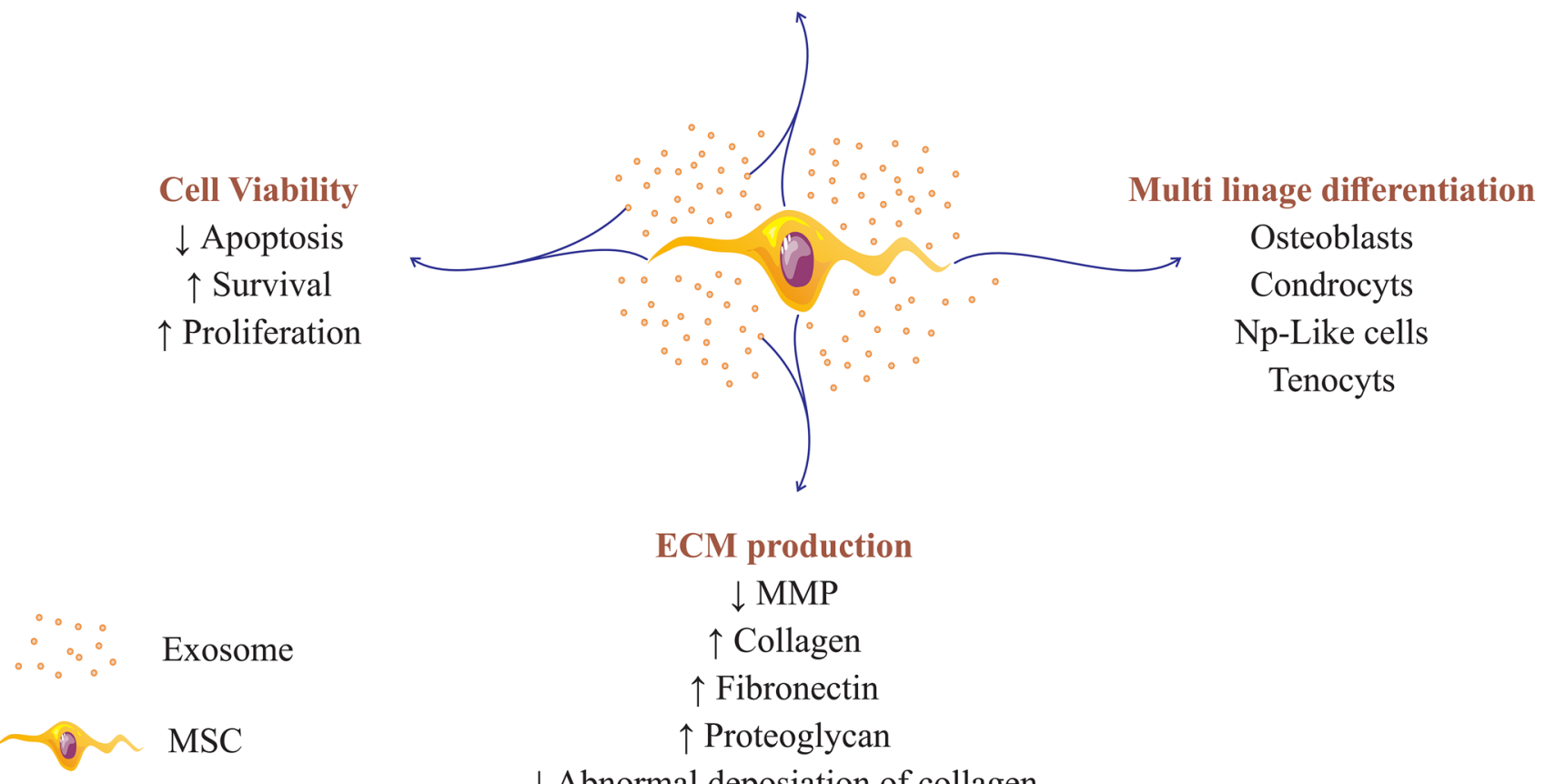

\author{
ECM production \\ $\downarrow$ MMP \\ $\uparrow$ Collagen \\ $\uparrow$ Fibronectin \\ $\uparrow$ Proteoglycan \\ $\downarrow$ Abnormal deposiation of collagen
}

Fig. 1 Mesenchymal stem cells and their exosome use various mechanisms to repair tissue in orthopedic diseases. So MSCs and MSCsderived exosomes can be increased extracellular matrix production, increased cell viability, immunomodulatory properties, and multiplication differentiation 
Table 4 Mechanisms of MSC and MSC-derived exosomes involved in regenerative medicine abbreviation

\begin{tabular}{|c|c|c|}
\hline disorders & MSC related mechanisms & MSC derived exosome related mechanisms \\
\hline $\begin{array}{l}\text { bone regeneration } \\
\text { and Osteoporosis } \\
\text { improvement }\end{array}$ & $\begin{array}{l}\text { 1. increased monocyte differentiation to M2 macrophage } \\
\text { 2. decreased production of proinflammatory cytokines } \\
\text { such as IL- } 6 \text {, IL-1, and TNF-a } \\
\text { 3. Migration to bone injury site by specific chemokine } \\
\text { receptors } \\
\text { 4. Stimulation of osteoblastic differentiation } \\
\text { 5. Increase angiogenesis at the site of injury } \\
\text { 6. Creating a regenerating microenvironment } \\
\text { exosomes }\end{array}$ & $\begin{array}{l}\text { 1. carry osteogenic related mi-RNAs such as miR-196a, } \\
\text { miR-27a, and miR-206 } \\
\text { 2. increasing the recruitment of MSCs to the fracture site by } \\
\text { stimulation of MCP-1, MCP-3, and SDF-1 production } \\
\text { 3. increasing mineral deposition in osteoblasts } \\
\text { 4. increasing angiogenesis by stimulating VGEF expression } \\
\text { and suppress SPRED1 suppression } \\
\text { 5. increasing the differentiation of hMSCs into osteoblasts } \\
\text { by stimulating COL1, ALP expression } \\
\text { 6. increase MSC osteoblastic differentiation by activating } \\
\text { the BMP-2/Smad1/RUNX2 signaling pathway } \\
\text { 7. increasing survival, proliferation, and differentiation } \\
\text { MAPK signaling pathway in osteoblasts } \\
\text { 8. inhibit apoptosis in BM-MSCs by miR-1263 / Mob1 / } \\
\text { Hippo signaling pathway }\end{array}$ \\
\hline cartilage repair & $\begin{array}{l}\text { 1. producing ECM components such as collagen, } \\
\text { fibronectin, proteoglycans, and glycosaminoglycans } \\
\text { 2. prevent chondrocyte apoptosis } \\
\text { 3. modulate the immune microenvironment of the injury } \\
\text { site }\end{array}$ & $\begin{array}{l}\text { 1. create a regenerative environment for tissue repair } \\
\text { 2. stimulation of cell proliferation through adenosine } \\
\text { catalysis, enzymes ERK } 1 / 2 \text { and AKT } \\
\text { 3. increased extracellular matrix synthesis } \\
\text { 4. increase chondrocytes mitochondrial function by } \\
\text { transferring inactive glycolytic enzymes to them } \\
\text { 5. Inhibition the function of NF-kB transcription factor } \\
\text { 6. transmit anti-inflammatory factors }\end{array}$ \\
\hline IDD & $\begin{array}{l}\text { 1. stimulate proliferation in the NPCs } \\
\text { 2. differentiate to NP-like cells } \\
\text { 3. prevents abnormal deposition and aggregation of type } 1 \\
\text { collagen by MMP } 12 \text { and HSP } 47 \text { production } \\
\text { 4. increase angiogenesis and pain-inducing nerve fibers } \\
\text { growth } \\
\text { 5. exert immunomodulatory effects on NP cells }\end{array}$ & $\begin{array}{l}\text { 1. modulate the inflammatory environment } \\
\text { 2. increase proliferation in NPCs } \\
\text { 3. increase ECM production in NPCs } \\
\text { 4. decrease NPCs apoptosis via suppression PTEN } \\
\text { expression (by mir- } 21 \text { transmission) } \\
\text { 5. reducing the stress of the NPC } \\
\text { 6. reduce AGEs related endoplasmic reticulum stress in } \\
\text { NPCs }\end{array}$ \\
\hline tendon & $\begin{array}{l}\text { 1. immunomodulatory effect } \\
\text { 2. differentiate to tenocytes } \\
\text { 3. stimulate proliferation and differentiation } \\
\text { in CD } 146 \text { + progenitor cells by the FAK/ERK } 1 / 2 \text { signal- } \\
\text { ing pathway }\end{array}$ & $\begin{array}{l}\text { 1. increase the tendon stem cell migration } \\
\text { 2. increase the anti-inflammatory macrophages migration to } \\
\text { the site of injury } \\
\text { 3. increase the expression of COL1al and COL3a1 }\end{array}$ \\
\hline
\end{tabular}

$E C M$ extracellular matrix, $T N F-a$ tumor necrosis factor alpha, $N F-k B$ Nuclear factor kappa-B, $I L$ interlukine, $M C P$ monocyte chemotactic protein, $S D F$ Stromal cell-derived factor, $R U N X 2$ Runt-related transcription factor 2, BMP bone morphogenic protein

in vivo and in vitro studies have shown the effectiveness of these cells in increasing bone regeneration. These cells' therapeutic effectiveness depends on various factors such as differentiation stage, injection method, and injection dose. These cells increase the regeneration of the bone in several ways [56]. 1) Decreased inflammation and immunomodulatory properties such as increased macrophage differentiation to M2 phenotype and decreased production of proinflammatory cytokines [57] 2) Migration to bone injury site by specific chemokine receptors [58] 3) Stimulation of osteoblastic differentiation of injury cite cells [59] 4) Increased angiogenesis [60] 5) Creating a regenerating microenvironment [59]. Also, nowadays, MSCs are used to transmit genes to increase bone regeneration. The selected genes can be transferred to MSCs using viral vectors such as adenoviruses or non-viral vectors such as liposomes [61]. For example, it has been reported that Ad-BMP2-MSC grafting in rabbits is associated with new bone formation [62].

Various stimulatory factors such as bone morphogenic protein 2 (BMP-2) [63], BMP-7 [64], Wnt11 (that increase the osteogenic potential of BMP-9) [65], nanohydroxyapatite [10], and strontium [66] stimulate MSCs differentiation into osteoblasts.

MSC exosomes play an important role in bone regeneration by stimulating osteogenesis and angiogenesis while interacting with various cells, such as Bone marrow-derived MSCs (BM-MSCs) and endothelial cells [67]. BM-MSCs exosomes contain up-regulated levels of three osteogenic-related miRNAs, miR-196a, miR-27a, and miR-206, of which miR-196a is the most important exogenous osteogenic regulator [68, 69].

Successful bone regeneration is closely related to successful angiogenesis, and if angiogenesis is defective, 
bone regeneration will fail. MSCs exosomes are capture by endothelial cells, which activate the Hypoxia-inducible factors (HIF-1a) and produce VEGF [70]. This pathway leads to the activation of eNOS and, eventually, NO production, which, regulating ERK1/2 and activating the protein kinases ERK and c-Jun, independent of VEGF/VEGF-R2 signaling, leads to increased angiogenesis. Also, the HIF-1a increases angiogenesis by activating the PI3K / Akt signaling path [71]. However, it is essential to consider that the microenvironment properties affect the function of exosomes produced by MSCs. For example, it has been shown that the pre-angiogenesis and stimulatory features of osteoblastic differentiation by exosomes produced from bone marrow MSCs are impaired in cases with type 1 diabetes [72].

Statistical analysis shows that during the differentiation of MSCs into osteoblasts, nine miRNAs, including let-7a, miR199b, miR-218, miR-148a, miR-135b, miR-203, miR-219, miR-299- 5p and miR-302b, increase in MSCs exosomes, while expression of four miRNAs, including miR-221, miR155, miR-885-5p, miR-181a, and miR-320c decreases. Interestingly, all enriched miRNAs play a role in the activity and function of osteoblasts [73].

Numerous studies have demonstrated the effectiveness of MSCs exosomes in healing bone fractures. To ensure bone fracture healing, there must be three basic conditions: proper angiogenesis, proper ossification, and stabilization of the two fractures together. These exosomes improve bone fracture by increasing the migration of MSCs to the fracture site, increasing mineral deposition, as well as increasing angiogenesis, and increasing the differentiation of MSCs into osteoblasts by mir-21. MSC exosomes stimulate the expression of genes associated with osteoblastic differentiation and angiogenesis such as COL1, ALP, and VGEF[74] and contain bone repair-related cytokines such as monocyte chemotactic protein-1 (MCP-1), monocyte chemotactic protein-3 (MCP-3), stromal cell-derived factor-1 (SDF-1) that increases the healing of bone fractures. Given the characteristics of CD9 ${ }^{-1}$ mice, such as reduced bone repair and reduced exosome release from cells, it is hypothesized that defects in fracture healing in these mice compared to wild-type mice may be related to defect in exosome release. Studies have shown that injection of MSC exosomes increases the rate of fracture healing in $\mathrm{CD}^{-1-}$ mice [69].

Nonunion is one of the disorders that can occur after a bone fracture. Using BM-MSCs derived exosomes to Nonunion Prevention has been tested today. In vitro results show that these exosomes increase bone differentiation by activating the BMP-2/ Smad1/ RUNX2 signaling pathway [75]. Smad proteins bind to RUNX2 to stimulate the differentiation of endothelial cells at the fracture site into osteoblasts and regulate collagen expression in osteoblasts (Fig. 2). These findings suggest that the use of BM-MSCs derived exosomes may be a promising therapeutic approach in the treatment of bone graft fractures [76].

In a study by Liu et al. and colleagues, both in vitro and in vivo analyses showed that MSCs' exosomes under hypoxic stress improved bone fractures healing more than normal exosomes. Induction of hypoxia leads to more exosome production from MSCs, and these exosomes are better and more capture by other MSCs. Hypoxia also leads to increased expression of HIF- $1 \alpha$ in MSCs, which is a significant factor in the positive regulating of miR-126 expression. Thus, these exosomes contain large amounts of mir-126 and increase angiogenesis in endothelial cells by suppressing the expression of SPRED1 and activating the Ras/Erk signaling pathway. Besides, miR-126 has been shown to play an essential role in promoting angiogenesis during embryonic development by targeting PIK3R2, an inhibitor of angiogenic signals, and cell survival in response to VEGF [74].

\section{MSCs and Their Derived Exosomes Role in Osteoporosis Improvement and Prevention}

Osteoporosis is one of the most common age-related skeletal disorders that, in many cases, can lead to bone fractures, and its prevalence is higher in women than men [77, 78]. Hormonal, nutritional, behavioral, and genetic factors can contribute to osteoporosis development and progression $[79,80]$. Among them, estrogen and glucocorticoid deficiency are the most common causes of osteoporosis [81]. Disruption of bone metabolic mechanisms, such as osteoclast imbalance of bone digestion and osteoblast formation of new bone, can lead to osteoporosis [79, 82]. In the process of osteoporesis repairing, osteoblasts are very important, and their function is to secrete osteoids to regenerate bone. BM-MSCs can differentiate into osteoblast cells [83, 84]. So MSCs play a role in bone tissue homeostasis due to their osteogenic and adipogenic differentiation abilities under physiological conditions [85]. Maintaining a balance between these differentiation abilities is essential to preventing osteoporosis [86]. Studies show that estrogen at normal concentrations stimulates bone formation and inhibits adipocyte formation, while at high concentrations, it has an adverse effect [87, 88]. Mesenchymal stem cells lose their ability to maintain bone homeostasis due to aging, menopause, and ovariectomy leading to the accumulation of large numbers of fat cells in the bone, loss of bone mass, and eventually osteoporosis [89]. Osteoblasts proliferate, matured, and produce extracellular matrix proteins for bone formation [90]. Several osteoporosis treatments have been suggested, including 1) Antiresorptive drugs including estrogen, bisphosphonates, selective estrogen response modulators (SERMs), and monoclonal antibodies including 


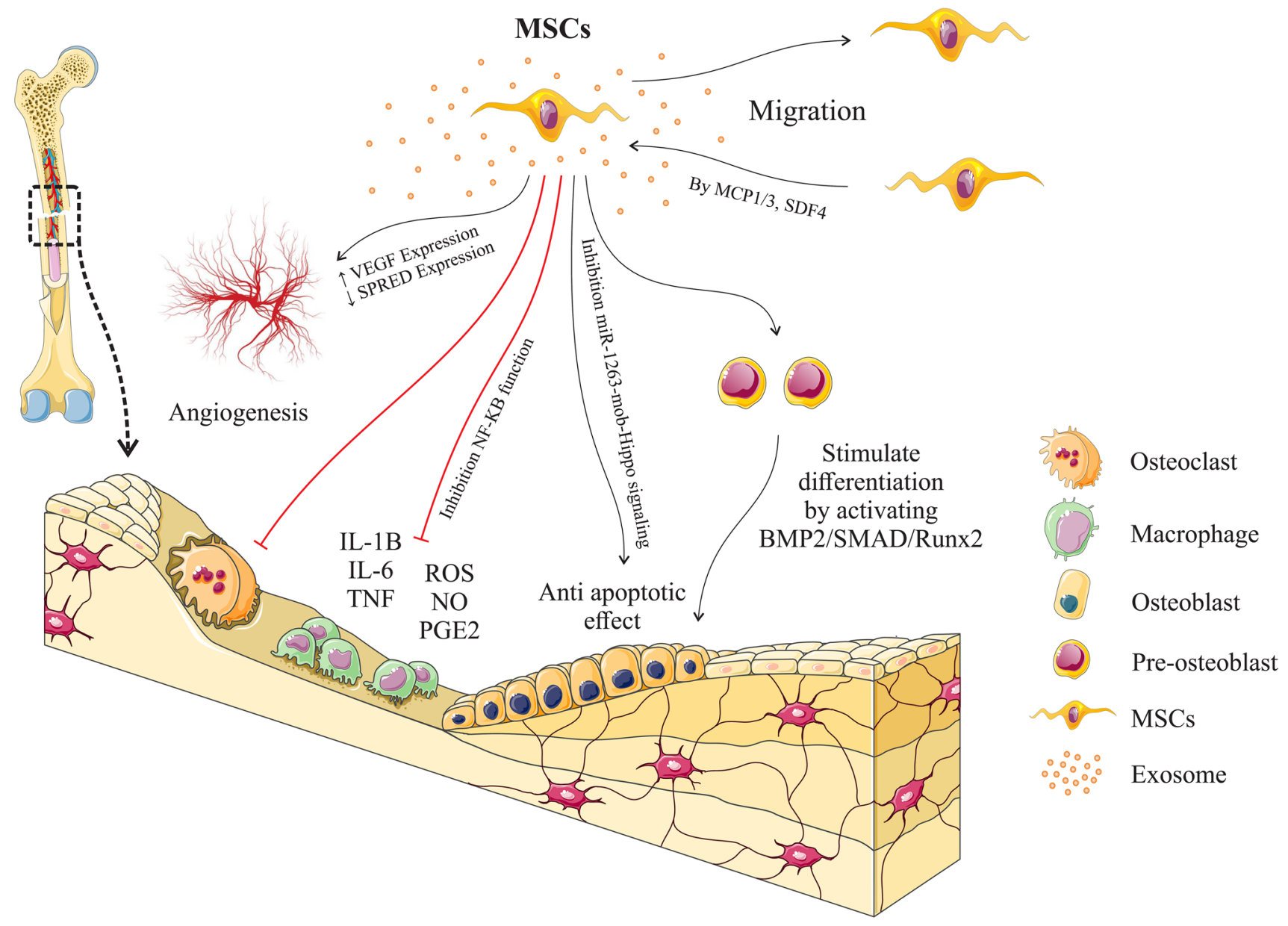

Fig. 2 Different functions of mesenchymal stem cell exosomes in bone fracture healing: These vesicles help bone healing by modulating the inflammatory environment, stimulating the differentiation of osteogenic progenitor cells into osteoblasts, stimulating angiogenesis,

denosumab. 2) Anabolic drugs, including Teriparatide (recombinant human parathyroid hormone), abaloparatide, and Wnt signaling pathway activators such as romosozumab 3) Combination therapies [91]. All of these treatments have side effects, so efforts to find new therapies are ongoing. Due to the reasons mentioned above, the use of mesenchymal stem cells and their exosomes can be a new treatment for osteoporosis.

A study states that MSCs derived exosomes improve and prevent osteoporosis by increasing survival, proliferation, and differentiation of osteoblast cell line (hFOB 1.19) via the mitogen-activated protein kinase (MAPK) signaling pathway, Whose molecular pathways are not currently known [92].

Exosomes of MSCs contain GLUT3 protein and mRNA. This protein is one of the most important osteoblast differentiation markers and maturation, which increases significantly in hFOB1.19 cells treated with exosomes derived from MSCs. Also the level of pro-caspase 3 and 9 increases, and the amount and stimulating the migration of circulating mesenchymal stem cells to the site of injury. Mesenchymal stem cells can also differentiate into other cells to help in the repairing process, leading to faster fracture healing

of broken caspase 3 and 9 decreases in these cells. According to the mentioned cases, these exosomes' use leads to increased proliferation and decreased apoptosis in the cell line related to osteoblast (hFOB1.19) [93].

In a study by Bao-cheng Yang et al., Human umbilical cord mesenchymal stem cell (HUC-MSCs) drived exosomes were used to treat hind limb unloading (HLU)induced osteoporosis in rats. The miR-1263 in these exosomes can bind directly to 3' UTRs of Mob1 and inhibit Mob1 expression. Inhibition of Mob1 activates YAP, a significant regulator of the Hippo signaling pathway, thus inhibiting HLU-induced apoptosis in BM-MSCs compared with controls. BM-MSCs are precursors of osteoblast lineage and prevent osteoporosis by differentiating into these cells. Therefore, this study states that exosomes derived from HUC-MSCs inhibit apoptosis in BM-MSCs and prevent osteoporosis in rats through the miR-1263 / Mob1 / Hippo signaling pathway [94]. 
Exosomes derived from BM-MSCs can effectively stimulate osteoblast activity and prevent osteoporosis. A study in this field states that BM-MSCs do this by a LncRNA called MALAT1. MALAT1 binds to miR-34c and inactivates it, which increases the expression of SATB2 in osteoblasts (hFOB1.19). SATB2 is the target gene for miR-34b/c. It is also a scaffold protein that enhances the activity of two transcription factors, Runx2 and ATF4, which play an essential role in strengthening osteogenic differentiation. Therefore, this study suggests that exosomal MALAT1 derived from BM-MSCs may increase osteogenic activity and reduce osteoporosis symptoms [95].

\section{MSCs and Their Derived Exosomes Role in Cartilage Repair and Regeneration}

Many studies have confirmed the therapeutic effect of MSC in cartilage repair in animal and clinical studies. Osteoarthritis (OA) is the most common form of chronic joint disease characterized by the destruction of articular cartilage, the destruction of menisci and ligaments, the thickening of subchondral bone, and the formation of osteophytes [96]. There is currently no cure for OA, and most OA treatments are prescribed to manage pain, stiffness, and swelling [97, 98]. Because articular cartilage damage is of particular importance for OA pathology, it is crucial to restoring the articular cartilage's integrity and function in stopping or reversing OA progression. However, repairing and regenerating damaged articular cartilage is challenging because cartilage generally has an inadequate healing capacity and also challenging to treat due to the low level of blood vessels and blood supply. In recent decades, MSCs have been used to repair cartilage tissue because of their ability to differentiate into different tissues, including cartilage tissue [99]. Various strategies, such as co-culture of MSCs with cartilage cells, have increased MSC differentiation into chondrocytes and improved these cells' regenerative properties. For example, Concomitant use of MSCs and chondrocyte differentiationinducing factors, such as TGF- $\beta$ superfamily activators [100], affects MSCs' proliferation and metabolic activity[101].

In large cartilage lesions, along with surgery, tissue engineering technology is used to recover cartilage tissue. Mesenchymal stem cells delay cartilage degeneration progression and lead to pain relief and improved function in patients with osteoarthritis and rheumatoid arthritis [101]. MSCs based Treatments for cartilage lesions include three groups. 1) MSCs transplantation 2) Injection of MSCs cells with scaffolds, and 3) Injection of MSCs-derived exosomes [102]. These cells improve cartilage function by increasing the production of ECM components such as collagen, fibronectin, proteoglycans, and glycosaminoglycans [103, 104]. MSCs can prevent chondrocyte apoptosis through the paracrine effect [105].

Over time, various studies have demonstrated the therapeutic effects of MSC derived exosomes in treating and recovering cartilage tissue [106]. MSCs exosomes may modulate the immune microenvironment to reduce the proinflammatory cell phenotype and create a regenerative environment for tissue repair [107, 108]. It has also been reported that the therapeutic efficacy of MSC derived exosomes does not depend on the tissue source of MSCs [109]. These exosomes perform therapeutic functions to regenerate cartilage through various mechanisms, including the transmission of biological mediators, stimulation of cell proliferation, increased extracellular matrix synthesis, and immunomodulatory properties [104].

Usually, during the aging process in mitochondria of chondrocytes, the proteins associated with the electron transport chain and ATP production decrease, and mitochondrial function is impaired [110]. In such a scenario, the capacity of the cartilage cells to repair is significantly reduced. MSC exosomes contain inactive glycolytic enzymes such as phosphoglucokinase and pyruvate kinase, ATP-producing enzymes such as adenylate kinase and nucleoside diphosphatase kinase $[32,111]$. It seems that the transfer of these enzymes by exosomes can compensate for the decreased ATP production in cartilage chondrocytes.

In order to regenerate cartilage tissue, it is vital to restore cell count, tissue structure, and function. MSC exosomes increase proliferation in various cells by phosphorylation through adenosine catalysis enzymes, ERK1/2 and AKT. Also, MSCs exosomes catalysis the adenosine production (activating survival kinases from Mediated by adenosine receptors) [112] from extracellular ATP released from damaged tissues (stimulates immune cells to kill damaged and stimulated cells) [113] with CD73 on their surface [114, 115].

In OA pathology, pro-inflammatory cytokines and matrix metalloproteinases (MMPs) [116] are mainly produced by the synovium and immune cells, such as macrophages, and play a role in the initiation and progression of OA. Therefore, modulation of the pro-inflammatory environment in damaged cartilage or OA is significant in cartilage regeneration. In various studies related to OA treatment with MSCs-derived exosomes [117], the concentrations of IL-1b and TNF-a, IL-6, MMPs, and NO are significantly reduced (due to the Inhibition of NF-kB) [118] and the secretion of IL-10 and TGF-b increases. These exosomes transmit anti-inflammatory factors such as hepatic growth factor (HGF), Heme oxygenase-1, TGF-B1, and stimulate the induction of suppressor cells such as Treg [119] and M2 macrophages in the region of inflammation and reduce cartilage damage and stimulate tissue regeneration (Fig. 3). 
Fig. 3 The effect of mesenchymal stem cell exosomes on cartilage regeneration: These exosomes help regenerate cartilage by repressing the immune system, stimulating the production of the extracellular matrix, and stimulating the proliferation and survival of chondrocytes through the ERK1/2 and AKT pathway

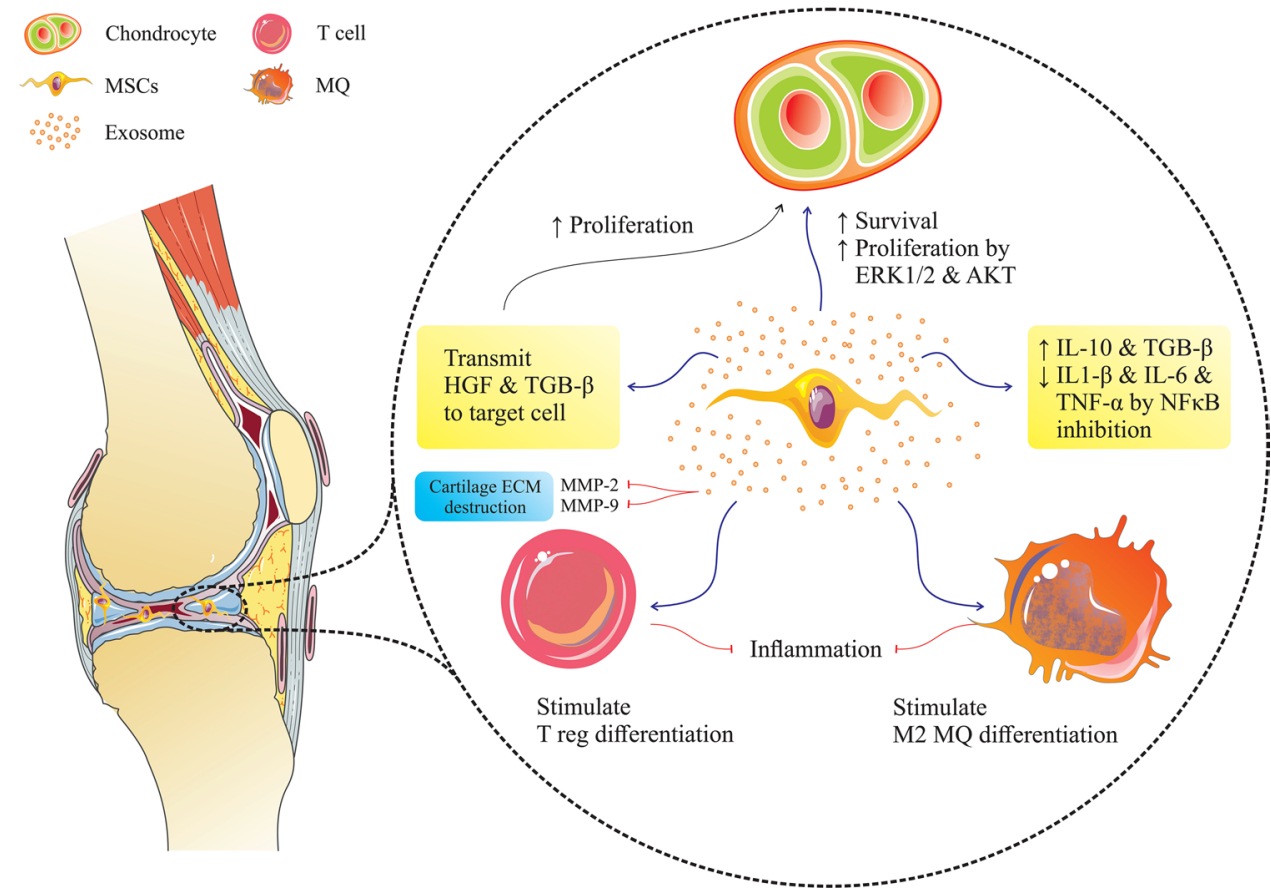

\section{MSCs and Their Derived Exosomes role in Aameliorate Intervertebral Disc Destruction(IDD) Treatment}

The intervertebral disc (IVD) is made up of the inner nucleus pulposus (NP) and the outer annulus fibrosus (AF), which act as the load-bearing and buffering unit of the spine [120]. Intervertebral disc disease (IDD) leads to back and neck pain [121], during which proinflammatory cytokine production and macrophage migration increase and extracellular matrix degradation occur [121, 122]. IDD progression begins and accelerates with NP cell depletion and ECM destruction [123]. One of the important signs of IDD is reducing the number of viable and functional cells and its replacement by a significant number of aging and apoptotic cells. The use of stem cells increases the viability of intervertebral disc cells and prevents disease progression [124]. Today, one of the most exciting treatments for this disease is the use of MSCs. After transplantation, MSCs can differentiate into NP-like cells and stimulate proliferation in NPCs, leading to intervertebral disc regeneration [125, 126]. Many studies have shown that the use of MSCs reduces IDD in many animal models but can not completely regenerate the disc [127]. Fibrosis is one of the leading causes of IDD that can be caused by inflammation or injury and autoimmune disorders.

Interestingly, MSCs transplantation prevents abnormal deposition and aggregation of type 1 collagen in the pulpous nucleus by modulating MMP12 and HSP47 mediators [128]. Mesenchymal stem cells increase angiogenesis and paininducing nerve fibers growth by decrease the inflammatory mediators through immunomodulatory effects on NPCs [129]. Also, MSCs are ameliorating IDD by their ability to differentiate into NPCs [130]. In order to increase the efficacy of MSCs in IDD treatment, these cells are incubated with NPC exosomes before transplantation to stimulate MSCs to differentiate into NP-like cells [124].

MSC exosomes modulate the inflammatory environment [129] and, after affecting NPCs, lead to increased proliferation, decreased apoptosis, and increased extracellular matrix production of these cells $[124,131]$. Due to the decrease in the amount of mir-21 in exhausted NPCs and the presence of high levels of mir-21 in MSCs exosomes, the addition of these exosomes to the exhausted NPCs reduces apoptosis and leads to suppression of PTEN expression by mir-21 transmission [126].

Advanced glycation end products (AGEs) produced by the Millard reaction typically accumulate in aging and damaged tissues and are closely related to inflammation, metabolic dysfunction, and endoplasmic reticulum (ER) stress. Since AGEs increase apoptosis in NPC by inducing ER stress and activating the unfolded protein response(UPR), inhibiting ER stress induced by AGEs can be a suitable therapeutic target for IDD treatment. MSCs exosomes inhibit apoptosis in these cells and inhibit disease progression by reducing the stress of the NPC endoplasmic reticulum containing AGEs by activating the AKT and ERK signaling pathways [103]. After the effect of MSCs derived exosomes on the exhausted NPCs, their proliferation was significantly increased compared to the control. The expression of Aggrecan, collagen II, sox-9, and TIMP-1 genes were also increased considerably. IL- $1 \beta$, iNOS, COX-2, IL-6, MMP13, MMP-1, MMP-3, and 
other enzymes involved in extracellular matrix degradation expression was significantly decreased so these cells can form a healthy extracellular matrix [132].

A new study has shown that miR-532-5p levels are decreased in apoptotic NPCs [133], while its amount in TNF- $\alpha$-stimulated bone marrow mesenchymal stem cell exosomes are very high [134]. TNF- $\alpha$ stimulated BMMSCs derived exosomes has better effects on NPCs than native BM-MSCs-Exos. miR-532-5p reduces apoptosis, ECM degradation, and fibrosis deposition by targeting RASSF5 (pro-apoptotic gene) 3'-UTR and silencing it [135].

Research has shown that the pathogenesis of IDD is closely related to ROS and oxidative stress [136]. Thus, attenuating mitochondrial dysfunction mediated by oxidative stress can increase the cellular homeostasis of NPCs and protect against IDD. A study by Chen Xia and colleagues shows that the use of $\mathrm{H} 2 \mathrm{O} 2$ leads to increased ROS and oxidative stress and leads to abnormal mitochondrial structure, increased ECM degrading enzymes, decreased ECM synthesis-related enzymes, increased NLRP3, and apoptosis in NPCs. MSC exosomes contain mitochondrial proteins and improve NPCs' mitochondrial function by transferring these proteins to them [132]. Studies show that these exosomes can merge with mitochondria mambrane after entering the NPCs. Besides, MSCs exosomes contain anti-oxidant proteins such as Trap 1, Gpx 4, and Prdx-1, preventing apoptosis by transporting them to cells containing oxidative stress [137].

\section{MSCs and their Exosomes Role in Tendon Repair}

Tendon damage occurs in athletes and physical activity and leads to severe pain. Also, people with multi-morbidity are more vulnerable to tendon damage as aging occurs. Today, MSC is used to repair tendons in many studies [138]. However, the direct use of MSC still faces inevitable challenges, such as operating costs, maintaining cell viability, and storage [139].

Because the Inhibition of exosome production by MSCs reduces their ability in tendon regeneration, the regenerative effect of MSCs may be exerted, at least in part, by exosomes [140]. Evidence suggests that MSCs derived exosomes can inhibit tendon stem cell apoptosis and stimulate their proliferation, migration, and tenogenic differentiation [141].

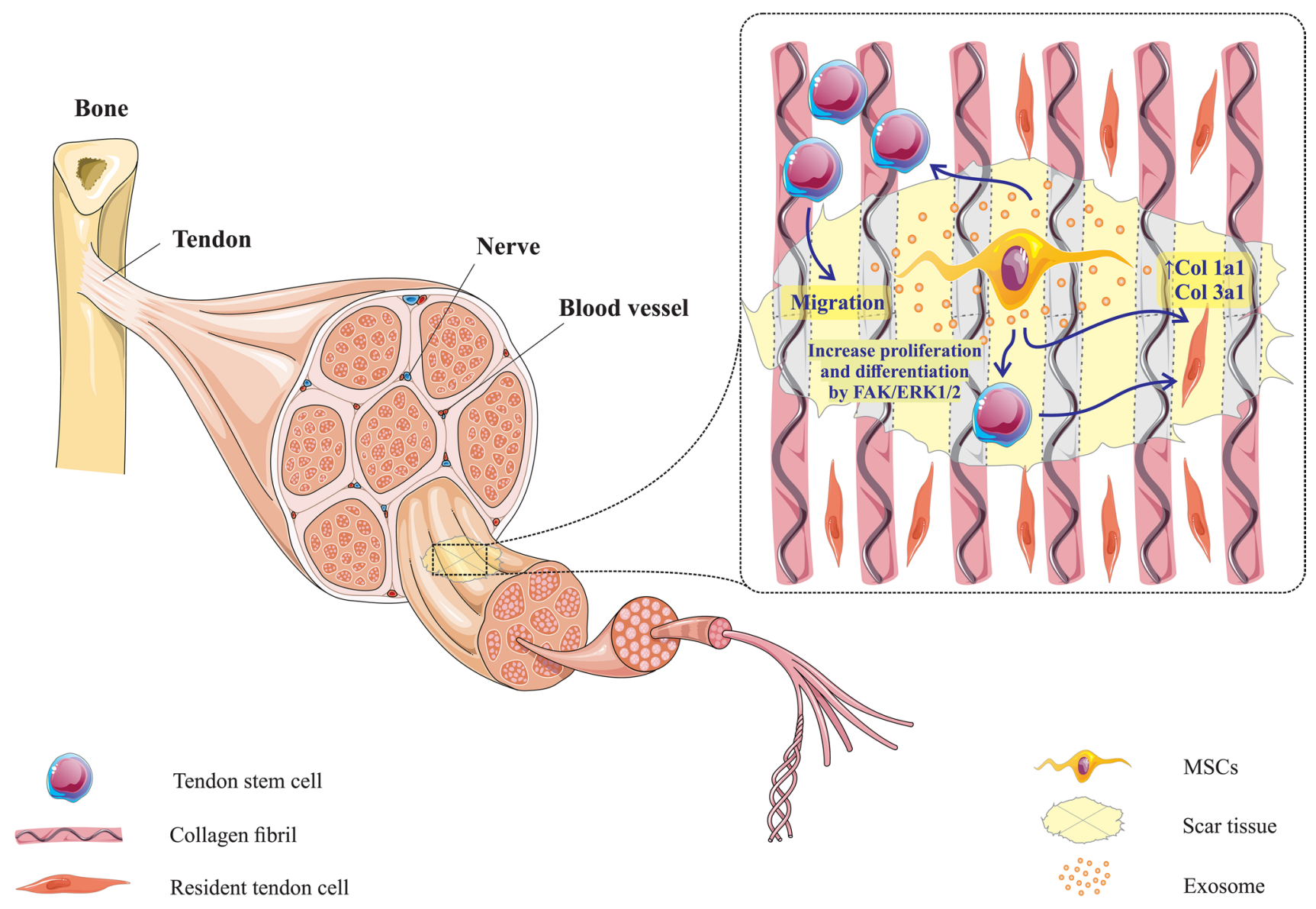

Fig. 4 Mesenchymal stem cell exosomes help regenerate tendon tissue by increasing tenogenesis of tendon stem cells through the SCX and TNmd pathways. Also, these exosomes increase the expression of COL1a1 and COL3a1 in the tendon cells present at the site of injury 
Inhibiting inflammation at the site of tendon damage is one of the first steps in tissue repairing. MSCs derived exosomes prevent inflammation by increasing the migration of CD163 + cells (markers of anti-inflammatory macrophages) to the tendon regeneration site. Also, the MSCs derived exosomes can affect macrophages and convert them to the M2 phenotype to participate in anti-inflammatory and regenerative reactions [142]. During this event, IL-10 and IL-4 cytokines' expression increased in macrophages, and the expression of interferon-gamma, IL-1B, and IL-6 cytokines decreased. These macrophages also increase angiogenesis by stimulating endothelial cell migration [143]. Studies show that the use of MSCs exosomes increases the CD146 + cell migration (tendon stem cell maker) to the site of injury [108]. These exosomes also stimulate the tenogenesis of tendon stem cells by stimulating mRNA expression of Scx and Tnmd genes (Fig. 4). These exosomes promote the expression of COL1a1, which encodes type I collagen, and COL3a1, which encodes type III collagen to regenerate the ECM in the injured Achilles tendon [144].

\section{Conclusion}

According to the above, mesenchymal stem cells and exosomes produced from them are one of the attractive fields in the treatment of various diseases. These cells and their exosomes can stimulate differentiation in the cells at the injury site and prevent cell apoptosis. Due to their immunomodulatory properties, they modulate inflammatory responses and prevent immune responses mediated disease. Mesenchymal stem cells produce chemotactic factors to recruit other stem cells and immune cells involved in tissue regeneration. Mesenchymal stem cells communicate with the surrounding cells by producing micro-vesicles, such as exosomes, and transmit various information. Although exosomes do not have cell transfer problems, their use is complicated due to their nanosize and are relatively expensive. Also, naive exosomes secreted by mesenchymal stem cells do not have much ability to induce optimal responses [145]. Therefore, today, by manipulating mesenchymal stem cells and their exosomes, increases their therapeutic application. These include loading various drugs into the exosomes for better efficiency. Drug loading in exosomes done through pre-load and post-load methods. In pre-load, by adding the cargos such as drugs, miRNA, and various proteins to mesenchymal stem cells' culture medium, they pick up the cargo and manifest inside the exosomes [146]. However, in the post-load method, after exosome isolation, the cargo is loaded in the exosome by various methods such as incubation, freeze-thaw, sonication, and electroporation [147]. Also, in some cases, by changing the exosomes' surface molecules, their efficiency can be increased for therapeutic purposes
[148]. However, using exosomes to treat various diseases is a new field in research, and its development can be a good platform for various applications.

Also, since there is no definitive treatment for orthopedic diseases, trying to induce tissue regeneration in the damaged tissues can be helpful in these diseases. Based on the above information, it can be concluded that the use of MSCs derived exosomes is one of the desired treatments that can stimulate this regeneration at the injury site.

Authors' Contributions Kosar Malekpour and Marziah Zahar wrote the manuscript, Ali Hazrati and Angelina Olegovna Zekiy edited final version of the manuscript, Jamshid G. Navashenaq and Alexander Markov draw the schematic figure and tables, Leila Roshangar and Majid Ahmadi designed and supervised the study, and correspondence during the paper submission.

Funding This study was supported by the Stem Cell Research Center at Tabriz University of Medical Sciences (Grant No. 67006).

Data Availability The data supporting the conclusions of this article are all online.

\section{Declarations}

Competing Interests The authors declare that they have no competing interests.

\section{References}

1. Metzger, J., \& Distl, O. (2020). Genetics of Equine Orthopedic Disease. Veterinary Clinics: Equine Practice, 36, 289-301.

2. Myojin, T., Ojima, T., Kikuchi, K., Okada, E., Shibata, Y., Nakamura, M., \& Hashimoto, S. (2017). Orthopedic, ophthalmic, and psychiatric diseases primarily affect activity limitation for Japanese males and females: based on the comprehensive survey of living conditions. Journal of Epidemiology, 27, 75-79.

3. Parekkadan, B., \& Milwid, J. M. (2010). Mesenchymal stem cells as therapeutics. Annual review of biomedical engineering, 12, 87-117.

4. Margiana, R., Aman, R. A., Pawitan, J. A., Jusuf, A. A., Ibrahim, N., Wibowo, H. (2019). The effect of human umbilical cordderived mesenchymal stem cell conditioned medium on the peripheral nerve regeneration of injured rats. Electronic Journal of General Medicine, 16.

5. Sarvar, D. P., Shamsasenjan, K., \& Akbarzadehlaleh, P. (2016). Mesenchymal stem cell-derived exosomes: new opportunity in cell-free therapy. Advanced Pharmaceutical Bulletin, 6, 293.

6. Han, Y., Li, X., Zhang, Y., Han, Y., Chang, F., \& Ding, J. (2019). Mesenchymal stem cells for regenerative medicine. Cells, 8, 886.

7. Smirnov, S. V., Harbacheuski, R., Lewis-Antes, A., Zhu, H., Rameshwar, P., \& Kotenko, S. V. (2007). Bone-marrow-derived mesenchymal stem cells as a target for cytomegalovirus infection: implications for hematopoiesis, self-renewal and differentiation potential. Virology, 360, 6-16.

8. Brown, C., McKee, C., Bakshi, S., Walker, K., Hakman, E., Halassy, S., et al. (2019). Mesenchymal stem cells: Cell therapy and regeneration potential. Journal of Tissue Engineering and Regenerative Medicine, 13, 1738-1755. 
9. Dominici, M., Le Blanc, K., Mueller, I., Slaper-Cortenbach, I., Marini, F., Krause, D., Deans, R., Keating, A., Prockop, D., \& Horwitz, E. (2006). Minimal criteria for defining multipotent mesenchymal stromal cells. The International Society for Cellular Therapy position statement, Cytotherapy, 8, 315-317.

10. Fitzsimmons, R.E., Mazurek, M.S., Soos, A., Simmons, C.A. (2018). Mesenchymal stromal/stem cells in regenerative medicine and tissue engineering, Stem Cells International.

11. Rasekh, H., Mehrabani, D., Farahi, M., Masoumi, S., Acker, J. (2020). Screening of Feijoa (Acca Sellowiana (O. Berg) Burret) Fruit Effect on Proliferation and Apoptosis using Bone Marrow derived Stem Cells Model. Electron Journal of General Medicine 17(6), em259, in, 2020.

12. Spaggiari, G. M., Capobianco, A., Abdelrazik, H., Becchetti, F., Mingari, M. C., \& Moretta, L. (2008). Mesenchymal stem cells inhibit natural killer-cell proliferation, cytotoxicity, and cytokine production: role of indoleamine 2, 3-dioxygenase and prostaglandin E2. Blood, The Journal of the American Society of Hematology, 111, 1327-1333.

13. Li, W., Ren, G., Huang, Y., Su, J., Han, Y., Li, J., Chen, X., Cao, K., Chen, Q., \& Shou, P. (2012). Mesenchymal stem cells: a double-edged sword in regulating immune responses. Cell Death \& Differentiation, 19, 1505-1513.

14. Gharibi, T., Ahmadi, M., Seyfizadeh, N., Jadidi-Niaragh, F., \& Yousefi, M. (2015). Immunomodulatory characteristics of mesenchymal stem cells and their role in the treatment of multiple sclerosis. Cellular Immunology, 293, 113-121.

15. Caplan, A. I. (2019). Mesenchymal stem cells in regenerative medicine, in: Principles of regenerative medicine. Elsevier, 219-227.

16. Luz-Crawford, P., Djouad, F., Toupet, K., Bony, C., Franquesa, M., Hoogduijn, M. J., Jorgensen, C., \& Noël, D. (2016). Mesenchymal stem cell-derived Interleukin 1 receptor antagonist promotes macrophage polarization and inhibits B cell differentiation. Stem Cells, 34, 483-492.

17. Ko, J. H., Lee, H. J., Jeong, H. J., Kim, M. K., Wee, W. R., Yoon, S.-O., Choi, H., Prockop, D. J., \& Oh, J. Y. (2016). Mesenchymal stem/stromal cells precondition lung monocytes/macrophages to produce tolerance against allo-and autoimmunity in the eye. Proceedings of the National Academy of Sciences, 113, 158-163.

18. Ge, W., Jiang, J., Arp, J., Liu, W., Garcia, B., \& Wang, H. (2010). Regulatory $\mathrm{T}$-cell generation and kidney allograft tolerance induced by mesenchymal stem cells associated with indoleamine 2, 3-dioxygenase expression. Transplantation, 90, 1312-1320.

19. Deng, Y., Zhang, Y., Ye, L., Zhang, T., Cheng, J., Chen, G., et al. (2016). Umbilical cord-derived mesenchymal stem cells instruct monocytes towards an IL10-producing phenotype by secreting IL6 and HGF. Scientific Reports, 6, 1-9.

20. Lai, F. W., Lichty, B. D., \& Bowdish, D. M. (2015). Microvesicles: ubiquitous contributors to infection and immunity. Journal of Leukocyte Biology, 97, 237-245.

21. Turturici, G., Tinnirello, R., Sconzo, G., \& Geraci, F. (2014). Extracellular membrane vesicles as a mechanism of cell-tocell communication: advantages and disadvantages. American Journal of Physiology-Cell Physiology, 306, C621-C633.

22. Koniusz, S., Andrzejewska, A., Muraca, M., Srivastava, A. K., Janowski, M., \& Lukomska, B. (2016). Extracellular vesicles in physiology, pathology, and therapy of the immune and central nervous system, with focus on extracellular vesicles derived from mesenchymal stem cells as therapeutic tools. Frontiers in Cellular Neuroscience, 10, 109.

23. Lai, C. P. -K., \& Breakefield, X. O. (2012). Role of exosomes/ microvesicles in the nervous system and use in emerging therapies. Frontiers in Physiology, 3, 228.

24. Hessvik, N. P., \& Llorente, A. (2018). Current knowledge on exosome biogenesis and release. Cellular and Molecular Life Sciences, 75, 193-208.
25. Zhang, H., Freitas, D., Kim, H. S., Fabijanic, K., Li, Z., Chen, H., et al. (2018). Identification of distinct nanoparticles and subsets of extracellular vesicles by asymmetric flow field-flow fractionation. Nature Cell Biology, 20, 332-343.

26. Vader, P., Mol, E. A., Pasterkamp, G., \& Schiffelers, R. M. (2016). Extracellular vesicles for drug delivery. Advanced Drug Delivery Reviews, 106, 148-156.

27. Soares, A. R., Martins-Marques, T., Ribeiro-Rodrigues, T., Ferreira, J. V., Catarino, S., Pinho, M. J., et al. (2015). Gap junctional protein $\mathrm{Cx} 43$ is involved in the communication between extracellular vesicles and mammalian cells. Scientific Reports, 5, 1-14.

28. Pfeffer, S. R. (2010). Two Rabs for exosome release. Nature Cell Biology, 12, 3-4.

29. Vilaça-Faria, H., Salgado, A. J., \& Teixeira, F. G. (2019). Mesenchymal stem cells-derived exosomes: a new possible therapeutic strategy for Parkinson's disease? Cells, 8, 118.

30. Yu, B., Zhang, X., \& Li, X. (2014). Exosomes derived from mesenchymal stem cells. International Journal of Molecular Sciences, 15, 4142-4157.

31. Burrello, J., Monticone, S., Gai, C., Gomez, Y., Kholia, S., \& Camussi, G. (2016). Stem cell-derived extracellular vesicles and immune-modulation. Frontiers in Cell and Developmental Biology, 4, 83.

32. Arslan, F., Lai, R. C., Smeets, M. B., Akeroyd, L., Choo, A., Aguor, E. N., et al. (2013). Mesenchymal stem cell-derived exosomes increase ATP levels, decrease oxidative stress and activate PI3K/Akt pathway to enhance myocardial viability and prevent adverse remodeling after myocardial ischemia/reperfusion injury. Stem Cell Research, 10, 301-312.

33. Vrijsen, K. R., Maring, J. A., Chamuleau, S. A., Verhage, V., Mol, E. A., Deddens, J. C., et al. (2016). Exosomes from cardiomyocyte progenitor cells and mesenchymal stem cells stimulate angiogenesis via EMMPRIN. Advanced Healthcare Materials, 5, 2555-2565.

34. Ono, M., Kosaka, N, Tominaga, N., Yoshioka, Y., Takeshita, F., Takahashi, R. U., Yoshida, M., Tsuda, H., Tamura, K., Ochiya, T. (2014). Exosomes from bone marrow mesenchymal stem cells contain a microRNA that promotes dormancy in metastatic breast cancer cells. Science Signaling, 7, ra63-ra63.

35. Di Trapani, M., Bassi, G., Midolo, M., Gatti, A., Kamga, P. T., Cassaro, A., Carusone, R., Adamo, A., \& Krampera, M. (2016). Differential and transferable modulatory effects of mesenchymal stromal cell-derived extracellular vesicles on $\mathrm{T}$. $B$ and NK cell functions, Scientific Reports, 6, 1-13.

36. Lou, G., Chen, Z., Zheng, M., \& Liu, Y. (2017). Mesenchymal stem cell-derived exosomes as a new therapeutic strategy for liver diseases. Experimental \& Molecular Medicine, 49, e346-e346.

37. McKelvey, K. J., Powell, K. L., Ashton, A. W., Morris, J. M., \& McCracken, S. A. (2015). Exosomes: mechanisms of uptake. Journal of Circulating Biomarkers, 4, 7.

38. Riau, A. K., Ong, H. S., Yam, G. H., \& Mehta, J. S. (2019). Sustained delivery system for stem cell-derived exosomes. Frontiers in Pharmacology, 10, 1368.

39. Joo, H. S., Suh, J. H., Lee, H. J., Bang, E. S., \& Lee, J. M. (2020). Current knowledge and future perspectives on mesenchymal stem cell-derived exosomes as a new therapeutic agent. International Journal of Molecular Sciences, 21, 727.

40. Mendt, M., Rezvani, K., \& Shpall, E. (2019). Mesenchymal stem cell-derived exosomes for clinical use. Bone Marrow Transplantation, 54, 789-792.

41. Nakano, M., Kubota, K., Kobayashi, E., Chikenji, T. S., Saito, Y., Konari, N., \& Fujimiya, M. (2020). Bone marrow-derived mesenchymal stem cells improve cognitive impairment in an 
Alzheimer's disease model by increasing the expression of microRNA-146a in hippocampus. Scientific Reports, 10, 1-15.

42. Baharlooi, H., Azimi, M., Salehi, Z., \& Izad, M. (2020). Mesenchymal stem cell-derived exosomes: a promising therapeutic ace card to address autoimmune diseases. International Journal of Stem Cells, 13, 13.

43. Harrell, C. R., Jovicic, N., Djonov, V., Arsenijevic, N., \& Volarevic, V. (2019). Mesenchymal stem cell-derived exosomes and other extracellular vesicles as new remedies in the therapy of inflammatory diseases. Cells, 8, 1605.

44. Ha, D. H., Kim, H.-K., Lee, J., Kwon, H. H., Park, G.-H., Yang, S. H., Jung, J. Y., Choi, H., Lee, J. H., \& Sung, S. (2020). Mesenchymal stem/stromal cell-derived exosomes for immunomodulatory therapeutics and skin regeneration. Cells, 9, 1157.

45. Li, M., Li, S., Du, C., Zhang, Y., Li, Y., Chu, L., Han, X., Galons, H., Zhang, Y., Sun, H. (2020). Exosomes from different cells: Characteristics, modifications, and therapeutic applications. European Journal of Medicinal Chemistry, 112784.

46. Lai, R. C., Tan, S. S., Teh, B. K., Sze, S. K., Arslan, F., De Kleijn, D. P., Choo, A., Lim, S. K., (2012). Proteolytic potential of the MSC exosome proteome: implications for an exosome-mediated delivery of therapeutic proteasome. International Journal of Proteomics.

47. Steelman, L. S., Chappell, W. H., Abrams, S. L., Kempf, C. R., Long, J., Laidler, P., Mijatovic, S., Maksimovic-Ivanic, D., Stivala, F., \& Mazzarino, M. C. (2011). Roles of the Raf/MEK/ERK and $\mathrm{PI} 3 \mathrm{~K} / \mathrm{PTEN} / \mathrm{Akt} / \mathrm{mTOR}$ pathways in controlling growth and sensitivity to therapy-implications for cancer and aging. Aging (Albany $N Y), 3,192$.

48. Shahabipour, F., Banach, M., \& Sahebkar, A. (2016). Exosomes as nanocarriers for siRNA delivery: paradigms and challenges. Archives of Medical Science, 12, 1324-1326.

49. Guy, R., \& Offen, D. (2020). Promising Opportunities for Treating Neurodegenerative Diseases with Mesenchymal Stem CellDerived Exosomes. Biomolecules, 10, 1320.

50. Yi, Y. W., Lee, J. H., Kim, S. -Y., Pack, C. -G., Ha, D. H., Park, S. R., et al. (2020). Advances in analysis of biodistribution of exosomes by molecular imaging. International Journal of Molecular Sciences, 21, 665.

51. Smyth, T., Kullberg, M., Malik, N., Smith-Jones, P., Graner, M. W., \& Anchordoquy, T. J. (2015). Biodistribution and delivery efficiency of unmodified tumor-derived exosomes. Journal of Controlled Release, 199, 145-155.

52. Charoenviriyakul, C., Takahashi, Y., Morishita, M., Matsumoto, A., Nishikawa, M., \& Takakura, Y. (2017). Cell type-specific and common characteristics of exosomes derived from mouse cell lines: Yield, physicochemical properties, and pharmacokinetics. European Journal of Pharmaceutical Sciences, 96, 316-322.

53. Lai, C. P., Mardini, O., Ericsson, M., Prabhakar, S., Maguire, C. A., Chen, J. W., Tannous, B. A., \& Breakefield, X. O. (2014). Dynamic biodistribution of extracellular vesicles in vivo using a multimodal imaging reporter. ACS Nano, 8, 483-494.

54. Agrahari, V., Mandal, A., Agrahari, V., Trinh, H. M., Joseph, M., Ray, A., et al. (2016). A comprehensive insight on ocular pharmacokinetics. Drug Delivery and Translational Research, 6, 735-754.

55. Hadjiargyrou, M., \& O'Keefe, R. J. (2014). The convergence of fracture repair and stem cells: interplay of genes, aging, environmental factors and disease. Journal of Bone and Mineral Research, 29, 2307-2322.

56. Oryan, A., Kamali, A., Moshiri, A., \& Eslaminejad, M. B. (2017). Role of mesenchymal stem cells in bone regenerative medicine: what is the evidence? Cells, Tissues, Organs, 204, 59-83.

57. Moshiri, A., Oryan, A., \& Meimandi-Parizi, A. (2015). Synthesis, development, characterization and effectiveness of bovine pure platelet gel-collagen-polydioxanone bioactive graft on tendon healing. Journal of Cellular and Molecular Medicine, 19, 1308-1332.

58. Poser, L., Matthys, R., Schawalder, P., Pearce, S., Alini, M., Zeiter, S. (2014) A standardized critical size defect model in normal and osteoporotic rats to evaluate bone tissue engineered constructs. BioMed Research International.

59. Amin, H. D., Brady, M. A., St-Pierre, J.-P., Stevens, M. M., Overby, D. R., \& Ethier, C. R. (2014). Stimulation of chondrogenic differentiation of adult human bone marrow-derived stromal cells by a moderate-strength static magnetic field. Tissue Engineering Part A, 20, 1612-1620.

60. Formiga, F. R., Pelacho, B., Garbayo, E., Abizanda, G., Gavira, J. J., Simon-Yarza, T., Mazo, M., Tamayo, E., Jauquicoa, C., \& Ortiz-de-Solorzano, C. (2010). Sustained release of VEGF through PLGA microparticles improves vasculogenesis and tissue remodeling in an acute myocardial ischemia-reperfusion model. Journal of Controlled Release, 147, 30-37.

61. Zomorodian, E., Baghaban, M., (2012). Eslaminejad, Mesenchymal stem cells as a potent cell source for bone regeneration. Stem Cells International.

62. Riew, K., Wright, N., Cheng, S.-L., Avioli, L., \& Lou, J. (1998). Induction of bone formation using a recombinant adenoviral vector carrying the human BMP-2 gene in a rabbit spinal fusion model. Calcified Tissue International, 63, 357-360.

63. Ye, K., Liu, D., Kuang, H., Cai, J., Chen, W., Sun, B., et al. (2019). Three-dimensional electrospun nanofibrous scaffolds displaying bone morphogenetic protein-2-derived peptides for the promotion of osteogenic differentiation of stem cells and bone regeneration. Journal of Colloid and Interface Science, 534, 625-636.

64. Chen, F., Bi, D., Cheng, C., Ma, S., Liu, Y., \& Cheng, K. (2019). Bone morphogenetic protein 7 enhances the osteogenic differentiation of human dermal-derived CD105+ fibroblast cells through the Smad and MAPK pathways. International Journal of Molecular Medicine, 43, 37-46.

65. Zhu, J. H., Liao, Y. P., Li, F. S., Hu, Y., Li, Q., Ma, Y., et al. (2018). Wnt11 promotes BMP9-induced osteogenic differentiation through BMPs/Smads and p38 MAPK in mesenchymal stem cells. Journal of Cellular Biochemistry, 119, 9462-9473.

66. Bizelli-Silveira, C., Pullisaar, H., Abildtrup, L. A., Andersen, O. Z., Spin-Neto, R., Foss, M., \& Kraft, D. C. (2018). Strontium enhances proliferation and osteogenic behavior of periodontal ligament cells in vitro. Journal of Periodontal Research, 53, 1020-1028.

67. Narayanan, R., Huang, C.C., Ravindran, S. (2016). Hijacking the cellular mail: exosome mediated differentiation of mesenchymal stem cells. Stem Cells International.

68. Qin, Y., Wang, L., Gao, Z., Chen, G., \& Zhang, C. (2016). Bone marrow stromal/stem cell-derived extracellular vesicles regulate osteoblast activity and differentiation in vitro and promote bone regeneration in vivo. Scientific Reports, 6, 1-11.

69. Furuta, T., Miyaki, S., Ishitobi, H., Ogura, T., Kato, Y., Kamei, N., et al. (2016). Mesenchymal stem cell-derived exosomes promote fracture healing in a mouse model. Stem Cells Translational Medicine, 5, 1620-1630.

70. Zhang, Y., Hao, Z., Wang, P., Xia, Y., Wu, J., Xia, D., et al. (2019). Exosomes from human umbilical cord mesenchymal stem cells enhance fracture healing through HIF- $1 \alpha$-mediated promotion of angiogenesis in a rat model of stabilized fracture. Cell Proliferation, 52, e12570.

71. Zhu, Y., Jia, Y., Wang, Y., Xu, J., \& Chai, Y. (2019). Impaired bone regenerative effect of exosomes derived from bone marrow mesenchymal stem cells in type 1 diabetes. Stem Cells Translational Medicine, 8, 593-605.

72. Xu, J.-F., Yang, G.-H., Pan, X.-H., Zhang, S.-J., Zhao, C., Qiu, B.-S., Gu, H.-F., Hong, J.-F., Cao, L., \& Chen, Y. (2014). Altered 
microRNA expression profile in exosomes during osteogenic differentiation of human bone marrow-derived mesenchymal stem cells. PLoS ONE, 9, e114627.

73. Takeuchi, R., Katagiri, W., Endo, S., \& Kobayashi, T. (2019). Exosomes from conditioned media of bone marrow-derived mesenchymal stem cells promote bone regeneration by enhancing angiogenesis. PLoS One, 14, e0225472.

74. Liu, W., Li, L., Rong, Y., Qian, D., Chen, J., Zhou, Z., Luo, Y., Jiang, D., Cheng, L., \& Zhao, S. (2020). Hypoxic mesenchymal stem cell-derived exosomes promote bone fracture healing by the transfer of miR-126. Acta Biomaterialia, 103, 196-212.

75. Wang, C. L., Xiao, F., Wang, C. D., Zhu, J. F., Shen, C., Zuo, B., et al. (2017). Gremlin2 suppression increases the BMP-2-induced osteogenesis of human bone marrow-derived mesenchymal stem cells via the BMP-2/Smad/Runx2 signaling pathway. Journal of Cellular Biochemistry, 118, 286-297.

76. Zhang, L., Jiao, G., Ren, S., Zhang, X., Li, C., Wu, W., et al. (2020). Exosomes from bone marrow mesenchymal stem cells enhance fracture healing through the promotion of osteogenesis and angiogenesis in a rat model of nonunion. Stem Cell Research \& Therapy, 11, 1-15.

77. Sale, J. E., Beaton, D., \& Bogoch, E. (2014). Secondary prevention after an osteoporosis-related fracture: an overview. Clinics in Geriatric Medicine, 30, 317-332.

78. Sipos, W., Pietschmann, P., Rauner, M., Kerschan-Schindl, K., \& Patsch, J. (2009). Pathophysiology of osteoporosis. Wiener Medizinische Wochenschrift, 159, 230-234.

79. Sandhu, S. K., \& Hampson, G. (2011). The pathogenesis, diagnosis, investigation and management of osteoporosis. Journal of Clinical Pathology, 64, 1042-1050.

80. Aghebati-Maleki, L., Dolati, S., Zandi, R., Fotouhi, A., Ahmadi, M., Aghebati, A., Nouri, M., Kazem Shakouri, S., Yousefi, M. (2019). Prospect of mesenchymal stem cells in therapy of osteoporosis: a review. Journal of Cellular Physiology, 234, 8570-8578.

81. Curtis, E. M., Moon, R. J., Dennison, E. M., Harvey, N. C., \& Cooper, C. (2016). Recent advances in the pathogenesis and treatment of osteoporosis. Clinical Medicine, 16, 360.

82. Raisz, L. G. (2005). Pathogenesis of osteoporosis: concepts, conflicts, and prospects. The Journal of Clinical Investigation, 115, 3318-3325.

83. Chan, C.K., Gulati, G.S., Sinha, R., Tompkins, J.V., Lopez, M., Carter, A.C., Ransom, R.C., Reinisch, A., Wearda, T. (2018) Murphy, Identification of the human skeletal stem cell. Cell, 175 43-56. e21.

84. Bianco, P., Robey, P. G., Saggio, I., \& Riminucci, M. (2010). "Mesenchymal" stem cells in human bone marrow (skeletal stem cells): a critical discussion of their nature, identity, and significance in incurable skeletal disease. Human Gene Therapy, 21, 1057-1066.

85. Hu, L., Yin, C., Zhao, F., Ali, A., Ma, J., \& Qian, A. (2018). Mesenchymal stem cells: cell fate decision to osteoblast or adipocyte and application in osteoporosis treatment. International Journal of Molecular Sciences, 19, 360.

86. Wang, C., Meng, H., Wang, X., Zhao, C., Peng, J., \& Wang, Y. (2016). Differentiation of bone marrow mesenchymal stem cells in osteoblasts and adipocytes and its role in treatment of osteoporosis. Medical Science Monitor: International Medical Journal of Experimental and Clinical Research, 22, 226.

87. Zhuang, H., Zhang, X., Zhu, C., Tang, X., Yu, F., \& Cai, X. (2016). Molecular mechanisms of PPAR- $\gamma$ governing MSC osteogenic and adipogenic differentiation. Current Stem Cell Research \& Therapy, 11, 255-264.

88. Okazaki, R., Inoue, D., Shibata, M., Saika, M., Kido, S., Ooka, H., Tomiyama, H., Sakamoto, Y., \& Matsumoto, T. (2002). Estrogen promotes early osteoblast differentiation and inhibits adipocyte differentiation in mouse bone marrow stromal cell lines that express estrogen receptor (ER) $\alpha$ or $\beta$. Endocrinology, 143, 2349-2356.

89. Tokuzawa, Y., Yagi, K., Yamashita, Y., Nakachi, Y., Nikaido, I., Bono, H., Ninomiya, Y., Kanesaki-Yatsuka, Y., Akita, M., \& Motegi, H. (2010). Id4, a new candidate gene for senile osteoporosis, acts as a molecular switch promoting osteoblast differentiation. PLoS Genetics, 6, e1001019.

90. Hisham Zainal Ariffin, S., Manogaran, T., Zarina Zainol Abidin, I., Megat Abdul Wahab, R., Senafi, S. (2017). A perspective on stem cells as biological systems that produce differentiated osteoblasts and odontoblasts. Current Stem Cell Research \& Therapy, 12 247-259.

91. Cheng, C., Wentworth, K., \& Shoback, D. M. (2020). New frontiers in osteoporosis therapy. Annual Review of Medicine, $71,277-288$.

92. Zhao, P., Xiao, L., Peng, J., Qian, Y., \& Huang, C. (2018). Exosomes derived from bone marrow mesenchymal stem cells improve osteoporosis through promoting osteoblast proliferation via MAPK pathway. European Review for Medical and Pharmacological Sciences, 22, 3962-3970.

93. Xie, Y., Hu, J., Wu, H., Huang, Z., Yan, H., \& Shi, Z. (2019). Bone marrow stem cells derived exosomes improve osteoporosis by promoting osteoblast proliferation and inhibiting cell apoptosis. European Review for Medical and Pharmacological Sciences, 23, 1214-1220.

94. Yang, B.-C., Kuang, M.-J., Kang, J.-Y., Zhao, J., Ma, J.-X., \& Ma, X.-L. (2020). Human umbilical cord mesenchymal stem cell-derived exosomes act via the miR-1263/Mob1/Hippo signaling pathway to prevent apoptosis in disuse osteoporosis. Biochemical and Biophysical Research Communications, 524, 883-889.

95. Yang, X., Yang, J., Lei, P., \& Wen, T. (2019). LncRNA MALAT1 shuttled by bone marrow-derived mesenchymal stem cellssecreted exosomes alleviates osteoporosis through mediating microRNA-34c/SATB2 axis. Aging (Albany NY), 11, 8777.

96. Loeser, R. F., Goldring, S. R., Scanzello, C. R., \& Goldring, M. B. (2012). Osteoarthritis: a disease of the joint as an organ. Arthritis and Rheumatism, 64, 1697.

97. Liu, H., Gao, W., Yuan, J., Wu, C., Yao, K., Zhang, L., Ma, L., Zhu, J., Zou, Y., \& Ge, J. (2016). Exosomes derived from dendritic cells improve cardiac function via activation of CD4+ T lymphocytes after myocardial infarction. Journal of Molecular and Cellular Cardiology, 91, 123-133.

98. Toh, W. S., Lai, R .C., Hui, J. H. P., Lim, S. K. (2017). MSC exosome as a cell-free MSC therapy for cartilage regeneration: implications for osteoarthritis treatment, in: Seminars in cell \& developmental biology. Elsevier, 56-64.

99. Kim, M., Steinberg, D. R., Burdick, J. A., \& Mauck, R. L. (2019). Extracellular vesicles mediate improved functional outcomes in engineered cartilage produced from MSC/chondrocyte cocultures. Proceedings of the National Academy of Sciences, 116, $1569-1578$

100. Demoor, M., Ollitrault, D., Gomez Leduc, T., Bouyoucef, M., Hervieu, M., Fabre, H., Lafont, J., Denoix, J. M., Audigié, F., MalleinGerin, F. (2014). Cartilage tissue engineering: molecular control of chondrocyte differentiation for proper cartilage matrix reconstruction. Biochimica et Biophysica Acta (BBA)-General Subjects, 1840, 2414-2440.

101. Le, H., Xu, W., Zhuang, X., Chang, F., Wang, Y., \& Ding, J. (2020). Mesenchymal stem cells for cartilage regeneration. Journal of Tissue Engineering, 11, 2041731420943839.

102. Zhang, R., Ma, J., Han, J., Zhang, W., \& Ma, J. (2019). Mesenchymal stem cell related therapies for cartilage lesions and osteoarthritis. American Journal of Translational Research, 11, 6275 . 
103. Mastbergen, S. C., Saris, D. B., \& Lafeber, F. P. (2013). Functional articular cartilage repair: here, near, or is the best approach not yet clear? Nature Reviews Rheumatology, 9, 277.

104. Somoza, R. A., Welter, J. F., Correa, D., \& Caplan, A. I. (2014). Chondrogenic differentiation of mesenchymal stem cells: challenges and unfulfilled expectations. Tissue Engineering Part B: Reviews, 20, 596-608.

105. Csaki, C., Keshishzadeh, N., Fischer, K., \& Shakibaei, M. (2008). Regulation of inflammation signalling by resveratrol in human chondrocytes in vitro. Biochemical Pharmacology, 75, 677-687.

106. Zhang, S., Chu, W., Lai, R., Lim, S., Hui, J., \& Toh, W. (2016). Exosomes derived from human embryonic mesenchymal stem cells promote osteochondral regeneration. Osteoarthritis and Cartilage, 24, 2135-2140.

107. Swärd, P., Frobell, R., Englund, M., Roos, H., \& Struglics, A. (2012). Cartilage and bone markers and inflammatory cytokines are increased in synovial fluid in the acute phase of knee injury (hemarthrosis)-a cross-sectional analysis. Osteoarthritis and Cartilage, 20, 1302-1308.

108. Zhang, S., Chu, W., Lai, R., Hui, J., Lee, E., Lim, S., \& Toh, W. (2016). Human mesenchymal stem cell-derived exosomes promote orderly cartilage regeneration in an immunocompetent rat osteochondral defect model. Cytotherapy, 18, S13.

109. Yeo, Y., Wee, R. (2013). Efficiency of exosome production correlates inversely with the developmental maturity of MSC donor.

110. Vaamonde-García, C., Riveiro-Naveira, R. R., Valcárcel-Ares, M. N., Hermida-Carballo, L., Blanco, F. J., \& López-Armada, M. J. (2012). Mitochondrial dysfunction increases inflammatory responsiveness to cytokines in normal human chondrocytes. Arthritis \& Rheumatism, 64, 2927-2936.

111. Lai, R.C., Yeo, R.W.Y., Tan, S.S., Zhang, B., Yin, Y., Sze, N.S.K ., Choo, A., Lim, S.K. (2013). Mesenchymal stem cell exosomes: the future MSC-based therapy?, in: Mesenchymal stem cell therapy, Springer, 39-61.

112. Jacobson, K. A., \& Gao, Z. -G. (2006). Adenosine receptors as therapeutic targets. Nature Reviews Drug Discovery, 5, 247-264.

113. Chekeni, F. B., Elliott, M. R., Sandilos, J. K., Walk, S. F., Kinchen, J. M., Lazarowski, E. R., Armstrong, A. J., Penuela, S., Laird, D. W., \& Salvesen, G. S. (2010). Pannexin 1 channels mediate 'find-me'signal release and membrane permeability during apoptosis. Nature, 467, 863-867.

114. Colgan, S. P., Eltzschig, H. K., Eckle, T., \& Thompson, L. F. (2006). Physiological roles for ecto-5'-nucleotidase (CD73). Purinergic Signalling, 2, 351 .

115. Zhang, S., Chuah, S. J., Lai, R. C., Hui, J. H. P., Lim, S. K., \& Toh, W. S. (2018). MSC exosomes mediate cartilage repair by enhancing proliferation, attenuating apoptosis and modulating immune reactivity. Biomaterials, 156, 16-27.

116. Kapoor, M., Martel-Pelletier, J., Lajeunesse, D., Pelletier, J.-P., \& Fahmi, H. (2011). Role of proinflammatory cytokines in the pathophysiology of osteoarthritis. Nature Reviews Rheumatology, 7, 33.

117. Marigo, I., Dazzi F. (2011). The immunomodulatory properties of mesenchymal stem cells, in: Seminars in immunopathology, Springer, 593.

118. Tofiño-Vian, M., Guillén, M. I., del Caz, M. D. P., Silvestre, A., \& Alcaraz, M. J. (2018). Microvesicles from human adipose tissue-derived mesenchymal stem cells as a new protective strategy in osteoarthritic chondrocytes. Cellular Physiology and Biochemistry, 47, 11-25.

119. Zhang, B., Yin, Y., Lai, R. C., Tan, S. S., Choo, A. B. H., \& Lim, S. K. (2014). Mesenchymal stem cells secrete immunologically active exosomes. Stem Cells and Development, 23, 1233-1244.

120. Verfaillie, T., Garg, A. D., \& Agostinis, P. (2013). Targeting ER stress induced apoptosis and inflammation in cancer. Cancer Letters, 332, 249-264.
121. Priyadarshani, P., Li, Y., \& Yao, L. (2016). Advances in biological therapy for nucleus pulposus regeneration. Osteoarthritis and Cartilage, 24, 206-212.

122. Wang, J., Tian, Y., Phillips, K. L., Chiverton, N., Haddock, G., Bunning, R. A., Cross, A. K., Shapiro, I. M., Le Maitre, C. L., \& Risbud, M. V. (2013). Tumor necrosis factor $\alpha$-and interleukin-1 $\beta$-dependent induction of CCL3 expression by nucleus pulposus cells promotes macrophage migration through CCR1. Arthritis \& rheumatism, 65, 832-842.

123. Vergroesen, P. -P., Kingma, I., Emanuel, K. S., Hoogendoorn, R. J., Welting, T. J., van Royen, B. J., et al. (2015). Mechanics and biology in intervertebral disc degeneration: a vicious circle. Osteoarthritis and Cartilage, 23, 1057-1070.

124. Lu, K., Li, H. -Y., Yang, K., Wu, J. -L., Cai, X. -W., Zhou, Y., \& Li, C. -Q. (2017). Exosomes as potential alternatives to stem cell therapy for intervertebral disc degeneration: in-vitro study on exosomes in interaction of nucleus pulposus cells and bone marrow mesenchymal stem cells. Stem Cell Research \& Therapy, 8, 1-11.

125. Risbud, M. V., Shapiro, I. M., Vaccaro, A. R., \& Albert, T. J. (2004). Stem cell regeneration of the nucleus pulposus. The Spine Journal, 4, S348-S353.

126. Cheng, X., Zhang, G., Zhang, L., Hu, Y., Zhang, K., Sun, X., et al. (2018). Mesenchymal stem cells deliver exogenous miR21 via exosomes to inhibit nucleus pulposus cell apoptosis and reduce intervertebral disc degeneration. Journal of Cellular and Molecular Medicine, 22, 261-276.

127. Sakai, D. (2011). Stem cell regeneration of the intervertebral disk. The Orthopedic clinics of North America, 42, 555-562, viii.

128. Leung, V. Y., Aladin, D. M., Lv, F., Tam, V., Sun, Y., Lau, R. Y., et al. (2014). Mesenchymal stem cells reduce intervertebral disc fibrosis and facilitate repair. Stem Cells, 32, 2164-2177.

129. Krock, E., Rosenzweig, D. H., \& Haglund, L. (2015). The inflammatory milieu of the degenerate disc: is mesenchymal stem cellbased therapy for intervertebral disc repair a feasible approach? Current Stem Cell Research \& Therapy, 10, 317-328.

130. Han, I., Ropper, A. E., Konya, D., Kabatas, S., Toktas, Z., Aljuboori, Z., et al. (2015). Biological approaches to treating intervertebral disk degeneration: devising stem cell therapies. Cell Transplantation, 24, 2197-2208.

131. Lan, W. R., Pan, S., Li, H. Y., Sun, C., Chang, X., Lu, K., Jiang, C. Q., Zuo, R., Zhou, Y., Li, C. Q. (2019). Inhibition of the Notch1 pathway promotes the effects of nucleus pulposus cell-derived exosomes on the differentiation of mesenchymal stem cells into nucleus pulposus-like cells in rats. Stem Cells International.

132. Xia, C., Zeng, Z., Fang, B., Tao, M., Gu, C., Zheng, L., Wang, Y., Shi, Y., Fang, C., \& Mei, S. (2019). Mesenchymal stem cellderived exosomes ameliorate intervertebral disc degeneration via anti-oxidant and anti-inflammatory effects. Free Radical Biology and Medicine, 143, 1-15.

133. Zhao, B., Yu, Q., Li, H., Guo, X., \& He, X. (2014). Characterization of microRNA expression profiles in patients with intervertebral disc degeneration. International Journal of Molecular Medicine, 33, 43-50.

134. Zhang, Z., Yang, J., Yan, W., Li, Y., Shen, Z., \& Asahara, T. (2016). Pretreatment of cardiac stem cells with exosomes derived from mesenchymal stem cells enhances myocardial repair. Journal of the American Heart Association, 5, e002856.

135. Zhu, G., Yang, X., Peng, C., Yu, L., \& Hao, Y. (2020). Exosomal miR-532-5p from bone marrow mesenchymal stem cells reduce intervertebral disc degeneration by targeting RASSF5. Experimental Cell Research, 393, 112109.

136. Feng, C., Yang, M., Lan, M., Liu, C., Zhang, Y., Huang, B., Liu, H., Zhou, Y. (2017). ROS: crucial intermediators in the 
pathogenesis of intervertebral disc degeneration, Oxidative Medicine and Cellular Longevity.

137. Basit, F., Van Oppen, L. M., Schöckel, L., Bossenbroek, H. M., Van Emst-de Vries, S. E., Hermeling, J. C., Grefte, S., Kopitz, C., Heroult, M., Willems, P. H. (2017). Mitochondrial complex I inhibition triggers a mitophagy-dependent ROS increase leading to necroptosis and ferroptosis in melanoma cells. Cell Death \& Disease, 8, e2716-e2716.

138. Le, B. T., Wu, X. L., Lam, P. H., \& Murrell, G. A. (2014). Factors predicting rotator cuff retears: an analysis of 1000 consecutive rotator cuff repairs. The American Journal of Sports Medicine, $42,1134-1142$.

139. Leong, D. J., \& Sun, H. B. (2016). Mesenchymal stem cells in tendon repair and regeneration: basic understanding and translational challenges. Annals of the New York Academy of Sciences, 1383, 88-96.

140. Yu, H., Cheng, J., Shi, W., Ren, B., Zhao, F., Shi, Y., et al. (2020). Bone marrow mesenchymal stem cell-derived exosomes promote tendon regeneration by facilitating the proliferation and migration of endogenous tendon stem/progenitor cells. Acta Biomaterialia, 106, 328-341.

141. Lui, P.P.Y. (2020). Mesenchymal Stem Cell-Derived Extracellular Vesicles for the Promotion of Tendon Repair-an Update of Literature. Stem Cell Reviews and Reports, 1-11.

142. Wang, R., Ji, Q., Meng, C., Liu, H., Fan, C., Lipkind, S., et al. (2020). Role of gingival mesenchymal stem cell exosomes in macrophage polarization under inflammatory conditions. International Immunopharmacology, 81, 106030.

143. Chamberlain, C. S., Clements, A. E., Kink, J. A., Choi, U., Baer, G. S., Halanski, M. A., Hematti, P., \& Vanderby, R. (2019). Extracellular vesicle-educated macrophages promote early Achilles tendon healing. Stem Cells, 37, 652-662.

144. Shi, Z., Wang, Q., \& Jiang, D. (2019). Extracellular vesicles from bone marrow-derived multipotent mesenchymal stromal cells regulate inflammation and enhance tendon healing. Journal of Translational Medicine, 17, 1-12.

145. Yim, N., Ryu, S. -W., Choi, K., Lee, K. R., Lee, S., Choi, H., et al. (2016). Exosome engineering for efficient intracellular delivery of soluble proteins using optically reversible proteinprotein interaction module. Nature Communications, 7, 1-9.

146. Jafari, D., Shajari, S., Jafari, R., Mardi, N., Gomari, H., Ganji, F., Moghadam, M. F., Samadikuchaksaraei, A. (2020). Designer exosomes: a new platform for biotechnology therapeutics. BioDrugs, 1-20.

147. Haney, M. J., Klyachko, N. L., Zhao, Y., Gupta, R., Plotnikova, E. G., He, Z., Patel, T., Piroyan, A., Sokolsky, M., \& Kabanov, A. V. (2015). Exosomes as drug delivery vehicles for Parkinson's disease therapy. Journal of Controlled Release, 207, 18-30.

148. Zhang, Z., Dombroski, J. A., \& King, M. R. (2020). Engineering of exosomes to target cancer metastasis. Cellular and Molecular Bioengineering, 13, 1-16.

149. Mildmay-White, A., \& Khan, W. (2017). Cell surface markers on adipose-derived stem cells: a systematic review. Current Stem Cell Research \& Therapy, 12, 484-492.

150. Bourin, P., Bunnell, B. A., Casteilla, L., Dominici, M., Katz, A. J., March, K. L., Redl, H., Rubin, J. P., Yoshimura, K., \& Gimble, J. M. (2013). Stromal cells from the adipose tissue-derived stromal vascular fraction and culture expanded adipose tissue-derived stro$\mathrm{mal} / \mathrm{stem}$ cells: a joint statement of the International Federation for Adipose Therapeutics and Science (IFATS) and the International Society for Cellular Therapy (ISCT). Cytotherapy, 15, 641-648.

151. Yoshimura, K., Shigeura, T., Matsumoto, D., Sato, T., Takaki, Y., Aiba-Kojima, E., et al. (2006). Characterization of freshly isolated and cultured cells derived from the fatty and fluid portions of liposuction aspirates. Journal of Cellular Physiology, 208, 64-76.
152. Connick, P., Kolappan, M., Crawley, C., Webber, D. J., Patani, R., Michell, A. W., Du, M.-Q., Luan, S.-L., Altmann, D. R., \& Thompson, A. J. (2012). Autologous mesenchymal stem cells for the treatment of secondary progressive multiple sclerosis: an open-label phase 2a proof-of-concept study. The Lancet Neurology, 11, 150-156.

153. Samsonraj, R. M., Raghunath, M., Nurcombe, V., Hui, J. H., van Wijnen, A. J., \& Cool, S. M. (2017). Concise review: multifaceted characterization of human mesenchymal stem cells for use in regenerative medicine. Stem Cells Translational Medicine, 6, 2173-2185.

154. El-Ansary, M., Abdel-Aziz, I., Mogawer, S., Abdel-Hamid, S., Hammam, O., Teaema, S., \& Wahdan, M. (2012). Phase II trial: undifferentiated versus differentiated autologous mesenchymal stem cells transplantation in Egyptian patients with HCV induced liver cirrhosis. Stem Cell Reviews and Reports, 8, 972-981.

155. Kangari, P., Talaei-Khozani, T., Razeghian-Jahromi, I., \& Razmkhah, M. (2020). Mesenchymal stem cells: amazing remedies for bone and cartilage defects. Stem Cell Research \& Therapy, 11, $1-21$.

156. Sibov, T. T., Severino, P., Marti, L., Pavon, L., Oliveira, D., Tobo, P., Campos, A., Paes, A., Amaro, E., \& Gamarra, L. (2012). Mesenchymal stem cells from umbilical cord blood: parameters for isolation, characterization and adipogenic differentiation. Cytotechnology, 64, 511-521.

157. Musiał-Wysocka, A., Kot, M., Sułkowski, M., Badyra, B., \& Majka, M. (2019). Molecular and functional verification of Wharton's jelly Mesenchymal stem cells (WJ-MSCs) Pluripotency. International Journal of Molecular Sciences, 20, 1807.

158. Fan, J., Varshney, R. R., Ren, L., Cai, D., \& Wang, D.-A. (2009). Synovium-derived mesenchymal stem cells: a new cell source for musculoskeletal regeneration. Tissue Engineering Part B: Reviews, 15, 75-86.

159. Zhao, D., Cui, D., Wang, B., Tian, F., Guo, L., Yang, L., Liu, B., \& Yu, X. (2012). Treatment of early stage osteonecrosis of the femoral head with autologous implantation of bone marrow-derived and cultured mesenchymal stem cells. Bone, 50, 325-330.

160. Struys, T., Moreels, M., Martens, W., Donders, R., Wolfs, E., \& Lambrichts, I. (2011). Ultrastructural and immunocytochemical analysis of multilineage differentiated human dental pulp-and umbilical cord-derived mesenchymal stem cells. Cells, Tissues, Organs, 193, 366-378.

161. Vishwanath, V. R., Nadig, R. R., Nadig, R., Prasanna, J. S., Karthik, J., \& Pai, V. S. (2013). Differentiation of isolated and characterized human dental pulp stem cells and stem cells from human exfoliated deciduous teeth: An in vitro study. Journal of Conservative Dentistry: JCD, 16, 423.

162. Amiri, F., Halabian, R., Dehgan Harati, M., Bahadori, M., Mehdipour, A., Mohammadi Roushandeh, A., Habibi Roudkenar, M. (2015). Positive selection of Wharton's jelly-derived CD105+ cells by MACS technique and their subsequent cultivation under suspension culture condition: A simple, versatile culturing method to enhance the multipotentiality of mesenchymal stem cells. Hematology, 20 208-216.

163. Bharti, D., Shivakumar, S. B., Park, J.-K., Ullah, I., Subbarao, R. B., Park, J.-S., Lee, S.-L., Park, B.-W., \& Rho, G.-J. (2018). Comparative analysis of human Wharton's jelly mesenchymal stem cells derived from different parts of the same umbilical cord. Cell and tissue research, 372, 51-65.

164. Saito, S., Lin, Y. -C., Murayama, Y., Hashimoto, K., \& Yokoyama, K. (2012). Human amnion-derived cells as a reliable source of stem cells. Current Molecular Medicine, 12, 1340-1349.

165. Spitzhorn, L.S., Rahman, M.S., Schwindt, L., Ho, H.T., Wruck, W., Bohndorf, M., Wehrmeyer, S., Ncube, A., Beyer, I., Hagenbeck, 
C. (2017). Isolation and molecular characterization of amniotic fluid-derived mesenchymal stem cells obtained from caesarean sections. Stem Cells International.

166. Guo, Y.-R., Cao, Q.-D., Hong, Z.-S., Tan, Y.-Y., Chen, S.-D., Jin, H.-J., Tan, K.-S., Wang, D.-Y., Yan, Y., \& The origin, transmission and clinical therapies on coronavirus disease, . (2019). (COVID-19) outbreak-an update on the status. Military Medical Research, 7(2020), 1-10.

167. Tan, S. H. S., Wong, J. R. Y., Sim, S. J. Y., Tjio, C. K. E., Wong, K. L., Chew, J. R. J., Hui, J. H. P., Toh, W. S. (2020). Mesenchymal Stem Cell Exosomes in Bone Regenerative Strategies-A Systematic Review of Preclinical Studies. Materials Today Bio, 100067.

168. Xiang, C., Yang, K., Liang, Z., Wan, Y., Cheng, Y., Ma, D., Zhang, H., Hou, W., \& Fu, P. (2018). Sphingosine-1-phosphate mediates the therapeutic effects of bone marrow mesenchymal stem cell-derived microvesicles on articular cartilage defect. Translational Research, 193, 42-53.

169. Jin, Z., Ren, J., \& Qi, S. (2020). Human bone mesenchymal stem cells-derived exosomes overexpressing microRNA-26a-5p alleviate osteoarthritis via down-regulation of PTGS2. International Immunopharmacology, 78, 105946.

170. Chui, M. H., Boroujeni, A. M., Mandelker, D., Ladanyi, M. Soslow, R. A. (2020). Characterization of TP53-wildtype tubo-ovarian high-grade serous carcinomas: rare exceptions to the binary classification of ovarian serous carcinoma. Modern Pathology, 1-12.

171. Zhang, S., Wang, M., Ren, X., Hassan, A., Lai, R.C., Lim, S.K., Lee, E.H., Hui, J.H.P., Toh, W.S. (2020). Intra-articular injections of mesenchymal stem cell exosomes and hyaluronic acid improve structural and mechanical properties of repaired cartilage in a rabbit model, Arthroscopy: The Journal of Arthroscopic \& Related Surgery.

Publisher's Note Springer Nature remains neutral with regard to jurisdictional claims in published maps and institutional affiliations. 